\title{
DISCLAIMER
}

This report was prepared as an account of wolk sponsored by an agency of the United States Government. Neither the United States Goves nment nor any agency thereof, nor any of their employees, makes any warranty, express or implied, or assumes any legal liability or responsibility for the accuracy, completeness, or usefu ness of any information, apparatus, product, or process disclosed, or represents that its use would not infringe privately owned rights. Reference herein to any specific commercial product, process, or service by trade name, trademark, manufacturer, or otherwise does not necessarily constitute or imply its endorsement, recommendation, or favoring by the United States Government or any agency thereof. The views and opinions of authors expressed herein do not necessarily state or reflect those of the United States Government or any agency ther:of.

\section{Criticality Evaluation And Protocol For DOE-Owned Spent Nuclear Fuels}

D.A. Cresap, P. J. Sentieri, J. R. Wilson

H. H. Loo, L. L. Taylor, R. Shikashio

Published September 1995

\section{Idaho National Engineering Laboratory Lockheed Idaho Technologies Company Idaho Falls, Idaho 83415}

\author{
Prepared for the \\ U.S. Department of Energy \\ Assistant Secretary for Environmental Management \\ Under [DOE Idaho Operations Office \\ Contract DE-AC07-94ID13223
}




\section{DISCLAIMER}

Portions of this document may be illegible in electronic irnage products. Images are produced from the best available original document. 
Changing scope, budgets, and missions of the DOE complex have redirected efforts from the traditional handling and processing fuel toward eventual disposal.

One of the concerns regarding the disposal of fuel is the risk of a criticality. Previous performance assessment work provided a preliminaly evaluation of the probability and consequences of a criticality.

During a program review of the FY-94 PA in December 1994, several additional questions and issues were identified and will be further considered prior to development of a final Fissile Material Evaluation Protocol. This report is an initial attempt to provide the background and justification of a proposed fissile material evaluation protocol for DOE-owned fissile materials destined for permanent repository disposal. Additional considerations and reviews by stakeholders are anticipated before its acceptance.

Preparation of spent fuel/waste for inte-im storage and final disposal may include mechanical, physical, and chemical processes, and may differ for each of the various fuels and wastes due to chemical composition or criticality considerations associated with HEU fuels.

The disposal of SNF in a repository recuires consideration of the potential for a criticality. Though a number of means for preventing a criticality in a repository exist, in a previous study (reference SAND-94$2563 / 2 \& 3$, chapter 10 and Appendix Ei respectively), an initial attempt was made to estimate the frequency of occurrence of a criticality and define the consequences. In so doing, both accidental criticalities and experimental reactor transients were examined to help define the energy release rate and duration of the postulated criticality. Fealt trees were constructed to define the most probable criticality scenario. Defining the consequences of a criticality in a geological repository was accomplished by performing a performance assessment (PA) with the assumption that a criticality occurs during the 10,000 years prescribed by 40 CFR $191^{1}$. The PA defined the consequences of a criticality in terms of release of radionuclides to the accessible environment. With the consequences of a repository criticality defined, a scientific basis for SNF disposal, in the form of disposal criteria, could then be developed. Policy Act of 1992 Section 801 (public Law 102-486). [Ref. 5] However, it is not clear at this time what effect the recommendations will have on the environmental standards for the repository. 


\section{Executive Summary}

This report is a continuation of repository criticality evaluation work. It is intended to resolve questions left open by the previous study, which focused on high-enriched uranium in a tuff repository. Both the probability and consequences of a criticality were considered. A long-term, low-power, water-moderated criticality was the most likely of those considered. Its probability was low $\left(5 \times 10^{-8} / \mathrm{yr}\right.$ for the entire HEU inventory in the repository), but not low enough to be dismissed. The governing regulation, $40 \mathrm{CFR} 191$, allows an event to be dismissed if it has less than one chance in 10,000 of occurring in 10,000 years. This implies a regulatory concern threshold of $10^{-8} / \mathrm{yr}$. Even if such an event occurred, the repository inventory would still be dominated by the disposed fuel and waste and no significant additional releases would be expected.

A technical review of the FY-94 draft PA prompted this study. The issues identified related to verification of inventory data values, the applicability of computer codes, and a hydrologic issue (water table rise).

The need was identified for a method for dealing with unforeseen changes in the amount or types of fuel, or other conditions of disposal. A protocol was developed to address this need. It provides a framework for dealing with changes that arise using the existing PA results as a baseline reference for comparison.

The major categories of criticality investigated were: water-moderated with fast or slow reactivity insertion, dry (hard-spectrum) with fast or slow reactivity insertion, water-moderated on the surface due to human intrusion, and far field.

Fault trees were prepared to assess these scenarios. As a result of this study, the probability of a criticality in 10,000 years was revised from $3 \times 10^{-3}$ to $5 \times 10^{-4}$, primarily through the elimination of conservatism and correction of assumptions. A revised fault tree is included. Some additional criticality mechanisms were considered and rejected.

The presence of water is a major concern in criticality studies. The possibility of flooding due to water table rise had been dismissed in previous studies. Conservative models indicate that this is a defensible position.

The possibility of a silica moderated criticality was considered briefly. This low likelihood event became a national controversy and was reviewed in detail by several national labs. Excerpts of their conclusions are included in this report.

The preliminary study identified isotopes of concern for release and these were verified by several comparative methods. Most isotopes had similar ratios across source categories and those that did not could be accounted for by fuel or waste characteristics.

The ORIGEN2 code was validated to be sufficiently accurate for PA purposes for the low-power, long-term scenario considered in the criticality study.

It is expected that unforeseen changes will be identified prior to repository closure, resulting in revisions to the fuel inventory and perhaps entirely different types of fuel. In addition, various organizations have taken different approaches to criticality work according to their distinct charters and needs. The fact that spent fuel and waste will go to the same repository means that eventually differences in approach will have to be resolved. The existing structure of the RW/EM steering group provides a method for dealing with criticality issues. The repository task team in particular is appropriate for this task. In order to prevent duplication of expense, it would be desirable to use existing criticality studies as a base from which to evaluate changes that arise. We propose a method for jointly resolving criticality issues and scenario changes. 
1 For specific new fuel types or data changes, it is proposed to use the 1994 PA as a baseline for comparison. All proposed changes should be evaluated by a screening analysis. Results which would increase the probability or consequences of a criticality by more than $10 \%$ would be considered worthy of further detailed study. Those proposed increases of less than $10 \%$ would not be considered significant. Due to the controversial nature of this viork, some of the philosophical issues concerning acceptability of any risk associated with repository disposal may have to be revisited. 


\section{Table of Contents}

Foreword $\ldots \ldots \ldots \ldots \ldots \ldots \ldots \ldots \ldots \ldots \ldots \ldots \ldots \ldots \ldots \ldots \ldots \ldots \ldots \ldots \ldots \ldots \ldots$

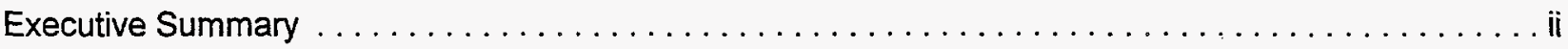

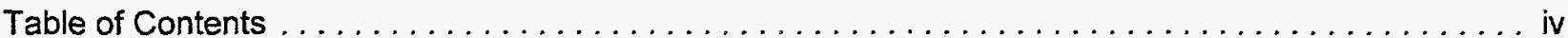

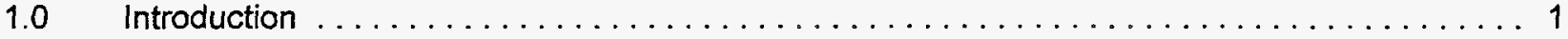

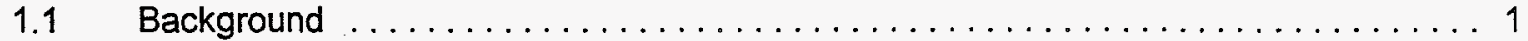

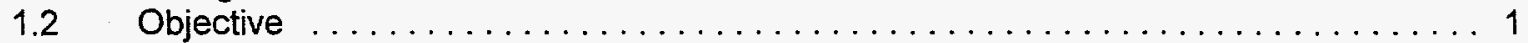

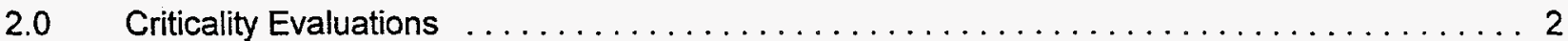

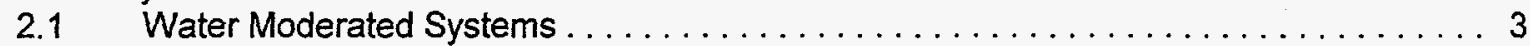

2.1.1 FY-94 DOE SNF Criticality Evaluation Basis and Results . . . . . . . . . . . 3

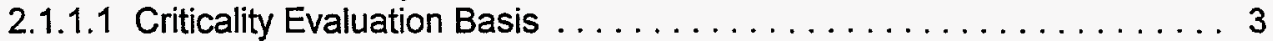

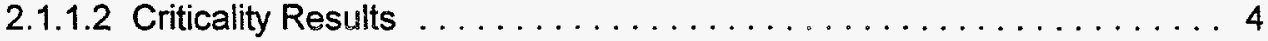

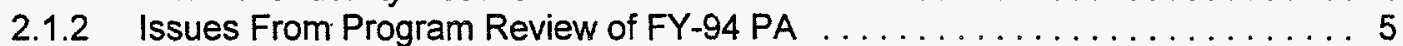

2.1.3 Evaluations to Resolve Identified Issues . . . . . . . . . . . . . . . . 5

2.1.3.1 DOE SNF Radionuclide Inventories . . . . . . . . . . . . . . . 5

2.1.3.2 Bounding Fission Product Calculation . . . . . . . . . . . . . 7

2.1.3.3 Water Table Rise . . . . . . . . . . . . . . . . . . . . . . . . . . . 7

2.2 Silica Moderated System $\ldots \ldots \ldots \ldots \ldots \ldots \ldots \ldots \ldots \ldots \ldots \ldots \ldots \ldots$

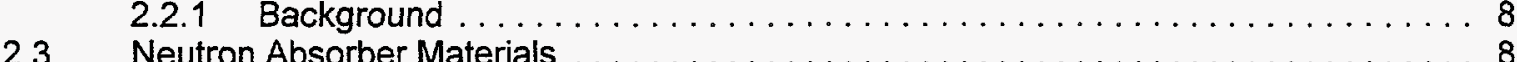

$3.0 \quad$ Criticality Evaluation Protocol $\ldots \ldots \ldots \ldots \ldots \ldots \ldots \ldots \ldots \ldots \ldots \ldots \ldots \ldots$

3.1 Criticality Evaluation Approaches . . . . . . . . . . . . . . . . . . . . . . 9

3.1.1 Office of Civilian Radioactive Waste Management System Approach . . . . . . . 9

3.1.2 DOE-Owned SNF Program Approach $\ldots \ldots \ldots \ldots \ldots \ldots \ldots \ldots \ldots \ldots \ldots$

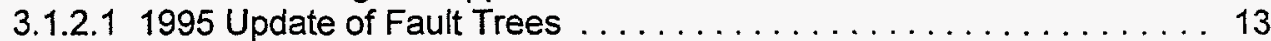

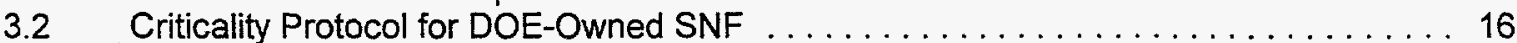

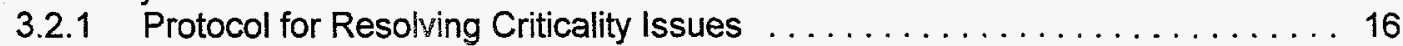

3.2.2 Predicting Repository Behavior . . . . . . . . . . . . . . . . . . . 18

3.2.3 Determine Acceptable Criteria . . . . . . . . . . . . . . . . 18

3.2.4 Assessment Beyond 10,000 Years . . . . . . . . . . . . . . . . . 20

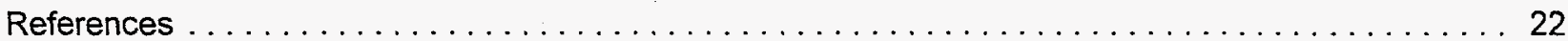

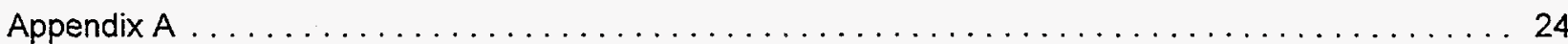

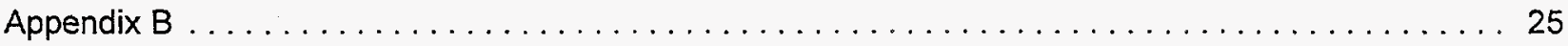

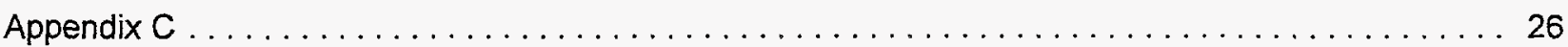

Appendix D . . . . . . . . . . . . . . . . . . 29 
This report is a continuation of repository criticality evaluation work. It is intended to resolve questions left open by the previous study.

\section{$1.1 \quad$ Background}

With the changes in world events, the demand to recover and recycle uranium had changed, and DOE discontinued reprocessing fuels for the recovery of high-enriched uranium (HEU) in April 1992. In the same year, the Idaho Chemical Processing Plant (ICPP) of the Idaho Netional Engineering Laboratory (INEL) initiated a new research program called the Spent Fuel and Waste Management Technology Development Program (SFWMTDP).

The SFWMTDP was tio perform directed research to develop an acceptable form for the disposal of waste materials and fuels currently stored at the INEL. Spent fuel is currently stored at the ICPP anc other INEL locations in various dry and wet storage facilities. High-level Waste (HLVV) disposal planning being prepared in conjunction with this development plan will address assumptions, regulatory drivers, and issues to be managed for proper treatment, storage, and disposal of HLW.

Major accomplishments and progress have been made in the past two years. These accomplishments included: (1) repackaging and moving deteriorating SNF located in an old storage pool to the modern wet storage pool that meets all current regulatory requirements, (2) finalizing the HLW form for final disposition, (3) initiating a performance assessment to assure the potential SNF and HLW waste forms have a very good chance of meeting the final disposition regulatory requirements, and (4) "Integration of all EM activities at the INEL" which (a) treats and stabilizes the maximum amount of waste and material for disposal, (b) accomplishes maximum volume reduction of wastes destined for repositories, (c) prepares the appropriate waste and material for shipment to the Waste Isolation Pilot Plant (W'PP) and the deep geologic repository, and (d) minimizes the total cost and risk by doing the work in the near-term rather than deferring it. On October 1994, the managemert and operation (M\&O) contract of the INEL was awarded to Lockheed Idaho Technologies Company. With a new M\&O contractor, additional expertise in various areas will provide further inputs to minimize cost and risk, and to maximize benefits with ongoing activities at the INEL.

The disposal of SNF ir a repository requires consideration of the potential for a criticality. This report is an initial attempt to provide: (1) the background and works completed to date in the area of criticality regarding final DOE-owned SNF disposition, and (2) a justification of a propo:sed criticality evaluation protocol for DOE-owned SNF destined for permanent repository disposal.

\subsection{Objective}

The objective of this diocument is to provide a foundation and basis which future criticality issues may build on. However, from the inception of this effort, the various participants understand that the criticality issue concerning the disposition of DOE-owned SNF in a permanent repository is no meager task and will require many iterations and scrutiny by the scientific community. The hope is that with each iteration, disposition of DOE-owned SNF will be a step closier to the repository. 


\subsection{Criticality Evaluations}

The SNF program recognized early on that criticality risk must be considered in the final disposition of DOE-owned SNF. Thus, criticality evaluation was initiated concurrently with the. performance assessment (PA) effort in FY-1993. During the initial PA effort, meetings were held to determine the best approach for performing this snormous task. The conclusion was to look at this problem in the most conservative manner and trim the conservatism through an iterative process as we better understood the issue.

In the FY-93 PA, two hypothetical repositories were considered. These were the bedded salt and igneous rock type repositories. At the time, the SNF and HLW program was directed by DOE not to consider Yucca Mountain as a potential repository site for the INEL SNF and HLW. Flow diagram 2.0 shows the criticality evaluations conducted and used in support of the FY-93 PA.

FIGURE 2.0 SIMPLIFIED FLOW DIAGRAM OF FY-93 PA CRITICALITY EVALUATION

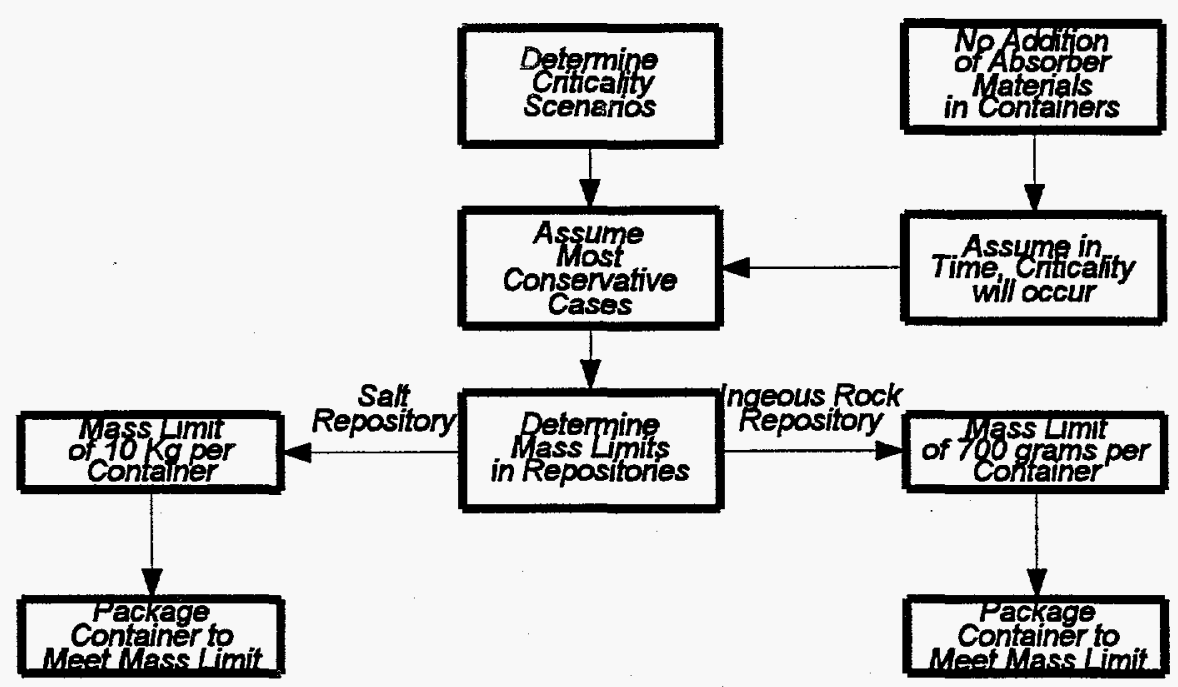

Subsequent to the initial evaluation, the FY-94 PA included a more detailed evaluation which makes up the majority of the information in this report. As the result of the FY-93 PA program review, a recommendation that future PA evaluation should be conducted in a Yucca Mountain type repository was concluded. Furthermore, the second recommendation states that a more realistic fissile material loading be considered in the FY-94 PA. As part of the evaluation, the consequences of a criticality scenario should also be considered. Based on these recommendations, the FY-94 PA approach to criticality was formulated and is indicated on Flow diagram 2.1. The hope is that further evaluation will improve the understanding of the criticality process and thus lead to an acceptable technical basis for resolving the criticality concerns of DOE-owned SNF in the repository. 


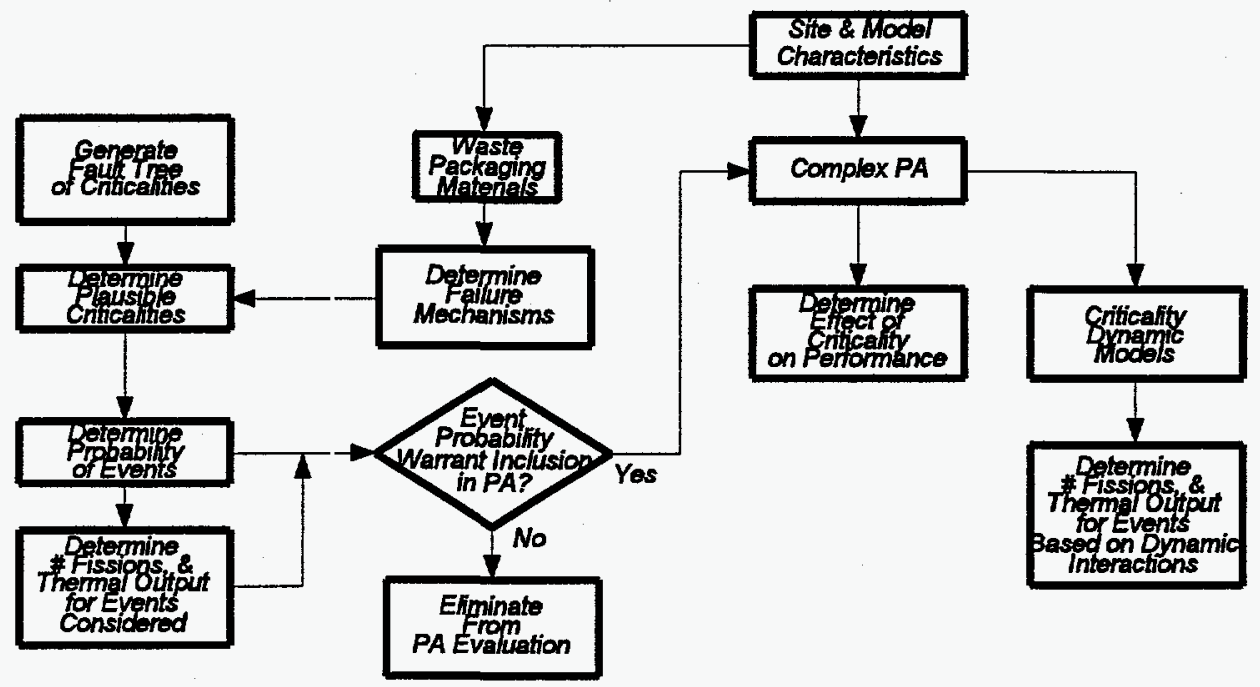

\subsection{Water Moderated Systems}

The FY-94 PA criticality evaluation reviewed various events and scenarios that could lead to a criticality. In the evaluation, both water moderated as well as unmoderated (dry) events were considered. The following section describes the basis of the FY-94 PA DOEowned SNF criticality evaluation.

\subsubsection{FY-94 DOE SINF Criticality Evaluation Basis and Results}

\subsubsection{Criticality Evaluation Basis}

In the FY-94 PA, an initial attempt was made to postulate the occurrence of a criticality and define the consequences in a tuff type repository. Since the main concern of criticality applies to high-enriched uranium, the evaluetion covered in FY-94 PA concentrated on the ATR (Advanced Test Fieactor), Shippingport, and graphite fuel types only. Detailed information on the evaluation may be found in the final FY-94 PA report SAND94-2563 Performance Assessment of Direct Disposal in Unsat urated Tuff of Spent Nuclear Fuel and High-Level Waste Owned by U. S. Department of Energy.

The fcllowing is a simplified task description of the evaluation. Although some of these tasks were conducted in parallel, these tasks are described sequentially for ease of understanding:

(1) Gather data on characteristics of the spent fuel and repository site.

(2) Examine both accidental criticalities and experimental reactor transients [Ref. 1] to help define the energy release rate and duration of the postulated criticality. 
(3) Identify waste package materials for the spent fuel.

(4) Develop and construct fault trees to define the most plausible criticality scenarios.

(5) Determine probability of criticality events, and number of fissions and thermal output for the events.

(6) Determine if the event probability warrants its inclusion into the PA evaluation.

(7) Model criticality scenarios to evaluate the following:

(a) Failure time of containers in repository environment

(b) Boron and uranium solubility in repository groundwater Based on the availability of water, calculate removal of uranium and boron from each container and uranium mineral precipitated

(d) Estimate the amount of uranium and water required in. the tuff pores to cause a criticality.

(e) Evaluate disruption of fluid flow from different sized heat sources and evaluate likely dynamics of the criticality; determining maximum fissions and time between criticality occurrences

(f) Evaluate the effects of increased heat and inventory on tuff type repository

\subsubsection{Criticality Results}

Although this evaluation was a first analysis of the criticality concern in a tuff repository, it has provided some important insights and results. The findings are summarized in the following sections.

\section{General Conclusions}

A water moderated criticality appears to be the most likely scenario if a criticality is to occur with the highly-enriched uranium (HEU) fuel in a MPC. The probability of such an event cannot be readily dismissed $\left(3 \times 10^{-7}\right.$ /year, value from FY-94 PA).

- Under the scenarios evaluated, the largest criticality event would be similar to any of the 16 reactors found at the Oklo site but at a lower power level of $1 \mathrm{~kW}$ and operating at a temperature of $\sim 100^{\circ} \mathrm{C}$ (atmospheric pressure) due to the fracture network throughout the repository.

Dynamics of the Criticality Event

Based on the EQ3/6 evaluation on solubility and the compositeporosity model, fissile material transported out of a container could be between 0.1 and $2.4 \mathrm{~kg}$ (EQ3/6 is a chemical equilibrium computer code). 
- $\quad$ Preliminary dynamic modeling (coupled with water availability to the repository) indicated that such a criticality would be cyclic in nature and will potentially operate for between 1 and 1,000 days.

- The criticality is extremely sensitive to water saturation in tuff.

\section{Consequences of Postulated Criticality}

- The consequences of such a criticality are insignificant from a stand point of heat and number of fissions. Assuming one container goes critical at a $1 \mathrm{~kW}$ power level for 10,000 years, it would only generate about $10^{25}$ fissions. Even if all of the HEU MPCs were to go critical for 10,000 years, the total nuclide inventory would be dominated by fuel representing $\sim 10^{30}$ fissions already disposed of at the repository.

- The gaseous fission products such as ${ }^{85} \mathrm{Kr}$ decay more rapidly than they are transported to the repository boundary.

\subsubsection{Issues From Program Review of FY-94 PA}

In early December, a Technical Peer Review Meeting and a DOE Program Review Meetirg were held to review the draft version of the FY-94 PA report. As a result of the two meetings, several open issues were identified. The open issues are liste:d below:

- Verify the ORIGEN2 run output data (radionuclide inventory) used in the FY-94 PA, especially the ${ }^{14} \mathrm{C}$ and other major contributing radionuclides Verify the acceptability of using the ORIGEN2 computer code to estimate the radionuclide inventories of a slow cooker

Verify that water table rise in the repository is not an issue

\subsubsection{Evaluations to Resolve Identified Issues}

The next three sections cover the evaluations completed in FY-95 to close the open issues identified in the FY-PA review. Due to funding constraints, some of the open issues identified will be evaluated in the coming years if funding allows.

\subsubsection{DOE SNF Radionuclide Inventories}

The original spent fuel nuclide inventories were developed from ORIGIEN2 computer runs. ORIGEN2 is a well established and validated computer code. However, our input data were estimates based on fuel data base information, and some of the fuels in the database had to be approximated by types that were more well known or unclassified. Having accepted the ORIGEN2 runs as valid, our primary emphasis in inventory validation was on verifying input and ensuring that the cases used were representative of the appropriate fuels. One method of validation that was performed for this study was a comparison of key nuclides across fuel types. These were calculated with several different methods of normalization. Although this is not a true validation by first principles, it did provide a comparison method to determine general agreeinent between fuel types and identify any suspicious values for 
further investigation. The spreadsheet used for the comparisons is given in Appendix A.

Preliminary studies identified a short list of nuclides that were the most likely to be of concern for releases. These were carbon-14, technetium99 , iodine-129, uranium-234, and neptunium-237. A further check on the inventory of these nuclides was performed to validate their values. First, the curies of these nuclides were compared between categories. Then, a comparison was made with a normalized value of curies/MTHM (Metric Tons Heavy Metal (Th, $U$, and $\mathrm{Pu})$ ). Finally, ratios of selected nuclides to the curie total per category were compared between categories. The ratios were not all consistent, but some of the discrepancies could be accounted for. For instance, variations in burnup explained some differences between curies/MTHM values. The curies of a selected nuclide per total curie inventory value was a better indicator of validity or discrepancy, but variations in initial enrichment caused variation between categories for actinides.

The ratio of curies to total curies gave roughly similar values for fission products $\left({ }^{99} \mathrm{Tc}\right.$ and $\left.{ }^{129} \mathrm{I}\right)$ and also for ${ }^{237} \mathrm{~Np}$. The ${ }^{234} \mathrm{U}$ values were not as consistent by either measure, but clustered roughly together for PWR, Nreactor, and Shippingport on the MTHM basis. The high burnup of the ATR fuel accounts for its $l o w{ }^{234} \mathrm{U}$ value, and the thorium in the graphite fuel accounts for its higher value.

Estimating the carbon-14 inventory was difficult because this nuclide is an activation product of nitrogen, which is present as an impurity in the fuel. Nitrogen impurity levels are not precisely known or consistent or uniformly distributed. Several ORIGEN2 test runs were performed to establish the effect of nitrogen $(\mathrm{N})$ on ${ }^{14} \mathrm{C}$. In general, ${ }^{14} \mathrm{C}$ increases with both initial $\mathrm{N}$ content and burnup. The relationship is not linear, so a determination of ${ }^{14} \mathrm{C}$ should be based on an ORIGEN2 run that is similar to desired conditions.

A series of spent fuel characterization studies was performed by Pacific Northwest Labs (Richland WA) by R. J. Guenther, et. al. (PNL-5109-103, $-104,-105$, and -106 ). These were based on PWR fuel that had approximately $28 \mathrm{ppm}$ nitrogen in the fuel pellets. Carbon-14 analysis varied widely from one fuel assembly to the next, even for assemblies with similar burnups and expected fission gases. The difference is attributed to the nitrogen content in the residual air in the rods. ORIGEN2 code results generally agreed with measured values of ${ }^{14} \mathrm{C}$ and differences were considered due to varying nitrogen content.

The low carbon-14 values for ATR fuels led us to suspect that the ATR run on which some of the inventory was based apparently did not account for the presence of nitrogen. The specifications for nitrogen in ATR fuel allowed for $1.4 \mathrm{gm} \mathrm{N} /$ element. ORIGEN2 runs performed for ATR fuel with this nitrogen content resulted in 1.5e-6 Ci/element of carbon-14. This level of ${ }^{14} \mathrm{C}$ is negligible compared to that present in fuel in other categories.

Another spreadsheet was prepared in the process of validating the inventory data. In this case, the projected DOE inventory was compared 
as a ratio to the projected Yucca mountain commercial inventory. Twelve nuclides that may be of concern for releases were selected, and Yucca mountain values for each were taken from both the Sandia TSPA report and the Intera report. The ratio of DOE curies to Yucca commercial curies was calculated for each nuclide. The resulting ratios clustered fairly ilosely in the 0.03 to 0.06 range. The DOE fuel showed a relative abunclance of U-235 due to the high enrichment of some DOE fuels. The enrichiment difference also explains a relatively low amount of U-234 in DOE fuel. The presence of thorium in some DOE fuels accounted for the high amounts of Pa-231 and U-233. Low DOE ratios for C-14 (0.005) and $1-129(0.014)$ are due to the removal of these nuclides from the waste during processing. This spreadsheet is included as Appendix B.

\subsubsection{Bounding Fission Product Calculation}

The scenario identified for criticality involves a long-duration low power reaction, resulting in the constant generation of fission products. This condition is outside the validated range of ORIGEN2 to predict invenlories, so an evaluation was performed to see if acceptable results could be determined by extrapolation. ORIGEN2 runs were performed under a range of conditions with regard to number and duration of steps. No more than ten percent variation in the output was observed as a result These results also agreed with hand calculations. The ten percent precision is considered to be sufficient for performance assessment work.

\subsubsection{Watel' Table Rise}

In several reviews with the Office of Civilian Radioactive Waste Management System (OCRWMS) in December 1994 and in 1995, water table ise was indicated to be a non-issue. Subsequent to a meeting held on March 1995, personnel of the OCRWMS (Peter Gottlieb, M\&O TRW Environmental Safety Systems inc.) provided excerpts of the National Reseiarch Council, "Ground Water at Yucca Mountain, How High Can it Rise", National Academy Press, Washington, D.C., 1992

The riferenced document was intended to assess the claim that near surface calcite deposits were evidence of flooding from a sub-surface source. The conclusion was that all the deposits came from surface sources. In addition, the report summarized current thinking on the possiljility of a significant water table rise in the future. The following items are typical of the limitations of possible future rises:

1. Of the possible explanations of calcite surface deposits the only one which involves surface flooding involves volcanic activity which produced the ash flow features in which the deposits occur. The last occurrence of this activity was 10 million years ago. (pg 3)

2. An evaluation of available evidence and studies indicates that the last ice age saw only a $40 \%$ increase in precipitation. (pg 6)

3. Modeling studies show that even conservative assumptions, such as a $100 \%$ increase in rainfall (and a corresponding 15 fold increase in recharge) would raise the water table only 150 meters. (pg 82) 
4. Fossil packrat middens approximately 50,000 years old indicate the water table in the recharge area east of Yucca Mountain was likely 100 meters above its present level, but no more than 160 meters above its present level (p. 78).

5. The probability of a magma dike intrusion close to the repository is less than $10^{-8}$ per year and scoping calculations suggest it would cause only a 10-15 meter rise in the water table. (pg 7)

6. One possible type of seismic-tectonic event which has been advanced as a possible initiator of repository flooding is a rupture in the low permeability zone imputed to be the source of the steep hydraulic gradient north of the site. A modeling study has indicated that should such a barrier exist, its removal would cause no more than a 40-meter rise in the water table at the repository site. (pg 72)

The report does not specifically state a probability for flooding as a function of time, but the above items are sufficient to conclude that the probability of flooding before 100,000 years is much less than 1 . This is consistent with one of the conclusions of the report that, "...the water table has not risen to the proposed repository level in the last 100,000 years..." (pg 5,6)

Since the water table rise to the proposed repository level has not occurred in the last 100,000 years and is not expected to rise to the proposed repository level in the next 100,000 years, this event will be treated as unlikely enough that it will not be included in any future performance assessment [Ref. 2]. This approach to water table rise is consistent with OCRWMS.

\subsection{Silica Moderated System}

In addition to the open issues indicated above, a silica moderated criticality was also identified as an area for further evaluation. However, due to funding constraints, this report will only cover the background and various technical positions to date. No specific evaluation will be conducted in FY-95.

\subsubsection{Background}

The National Academy of Science (NAS) paper [Ref. 3] has proposed that the weapon plutonium may be disposed of in vitrified high-level waste borosilicate glass logs. As the result of this recommendation, a third revision of a draft paper [Ref. 4] had been written suggesting the potential for a nuclear criticality in the geologic disposition of fissile materials. Prior to the third paper, the author released two other revisions in suggesting the potential of criticality of placing fissile materials in a repository. A review of various positions on silica moderated criticality systems appears in Appendix C.

\subsection{Neutron Absorber Materials}

With regard to criticality, several absorber materials may be used to minimize such a risk in an operating facility. These materials, excluding the gaseous materials, consist of large 
cross section elements; such as ${ }^{10} \mathrm{~B},{ }^{48} \mathrm{Cd}{ }^{64} \mathrm{Gd}$, and ${ }^{72} \mathrm{Hf}$. In the case of migration of material, other elements abundant in nature or with similar mobility to uranium may be effective in spite of smaller cross sections.

Reviewing the various materials available, certain elements such as ${ }^{48} \mathrm{Cd}$ were eliminated because of the Resources Conservation Recovery Act (RCRA) nature of the material. On the other hand, materials such as zirconium may be good absorber material because of the $3 \% \mathrm{Hf}$ naturally ocicurring with the zirconium. No specific selection has been finalized by the OCRWMS as tc neutron absorber materials to be used in the internals of the MPC. Several materials are being considered by the OCRWMS. They include: (1) Zirconium Hafnium Alloy 703, (2) Stainless Steel 316 with Boron (Borated SS), (3) Alloy 825 with Boron, (4) Stainless Steel, ceramic. At the present time, the borated SS (with natural Boron) appears to be inost economical. However, further studies may be necessary if enriched Boron is required to assure criticality safety in certain MPCs.

\subsection{Criticality Evaluation Protocı)}

As part of the criticality evaluation completed for the FY-94 PA, a criticality evaluation protocol for the DOE-owned SNF was also developed. This section covers the work completed to date and a proposed DOE-owned SNF criticality evaluation protocol for the future. It was recognized that such a protocol will represent aı proposal and may be updated when better approaches are identified between the OCRWMS and EM.

\subsection{Criticality Evaluation Approaches}

\subsubsection{Office of Civilian Radioactive Waste Management System Approach}

The OCRWMS has presently identified four time frames of interest pertaining to criticality evaluation. These time frames cover: (1) the Pre-closure period (up to 100 years), (2) the substantially complete containment period (100 to 1,000 years), (3) the waste isolation period ( 1,000 to 10,000 years), and (4) Limited release period (greater than 10,000 years).

Within these time periods of interest, the OCRWMS identified three possible criticality modes. They are: (1) the intact fuel mode, (2) the degraded fuel, internal mode, and (3) external mode. For the intact fuel mode, the following sequential events must occur in order for a criticality to happen: (1) corrosion of some holes in the outer and inner barriers, and (2) leaching of most of the neutron absorber from the basket material or stress corrosion cracking of stainless steel and redistribution within the canister. For the degraded fuel and internal to container mode, the following sequential events must occur in order for a criticality to happen: (1) corrosion of some holes in the outer and inner barriers, (2) leaching of most of the neutron absorber from the basket material, (3) corrosion of most of the basket structural material. Finally, for the external mode, the following sequential events must occur in order for a criticality to happen: (1) corrosion of some holes in the outer and inner barriers, (2) major breach of cladding, (3) dissolution of fissile material $\left({ }^{239} \mathrm{Pu}\right.$ or $\left.{ }^{235} \mathrm{U}\right)$, (4) transport of fissile material, and (5) adsorption of dissolved fissile material at points of concentration (away from the container). 
Pre-closure and substantially complete containment periods

From a criticality analysis standpoint, the pre-closure and substantial complete containment periods will be evaluated deterministically. This will show that each package will not go critical (and interactions between packages will not cause the package to go critical) considering the burnup credit and completely flooded waste package (maintaining all structural integrity but no additional neutron absorbers). During the containment period, another event which can lead to package breach includes flooding followed by anomalously fast corrosion. However, with the sequence of events required for a criticality to occur, a criticality is unlikely within the pre-closure and substantially complete containment periods.

Waste isolation period

For the waste isolation period, several additional events which can lead to criticality included: (1) removal of the added neutron absorber, and (2) collapse of basket or flux trap supports. In addition to the standard flooded package, OCRWMS is planning to conduct deterministic calculations of $K_{\text {eff }}$ for the configurations generated by the failure mode analysis (both intact and internal degraded criticality modes indicated above). In their initial analysis, the results still indicated a very low probability of such criticality occurring. The OCRWMS is in the process of completing these analyses and is planning to publish the results some time next year.

Limited release period

In addition to the events described above, the following events can also lead to external criticality. The events included: (1) dissolution, transport, and redeposition in a more concentrated manner of fissile material away from the container, and (2) migration into the rock to a configuration that is moderated by $\mathrm{SiO}_{2}$. For the limited release period, OCRWMS plans to perform criticality analysis through deterministic calculations of $\mathrm{K}_{\text {eff }}$ for the configurations having a significant probability (analyzing the above events). This analysis is at its planning stage and should be completed sometime late next year.

\subsubsection{DOE-Owned SNF Program Approach}

As indicated in section 2.1.1, the FY-94 PA criticality evaluation reviewed various events and scenarios that could lead to a criticality according to a systematic approach. Figure 3.1.2 is a flow diagram showing the steps completed in performing the evaluation. The flow diagram indicates the various aspects of criticality considered in the analysis as well as the actual analysis completed in support of the criticality analysis effort. There are still issues on the flow diagram which have not been closed out at this time. These areas are indicated on the flow diagram. In the process, the DOE-Owned SNF Program has acquired additional insight to the issue and will be proposing a improved criticality protocol in section 3.2. Details of the criticality analysis completed for the FY-94 PA may be found in SAND-94-2563/3, Appendix B. 


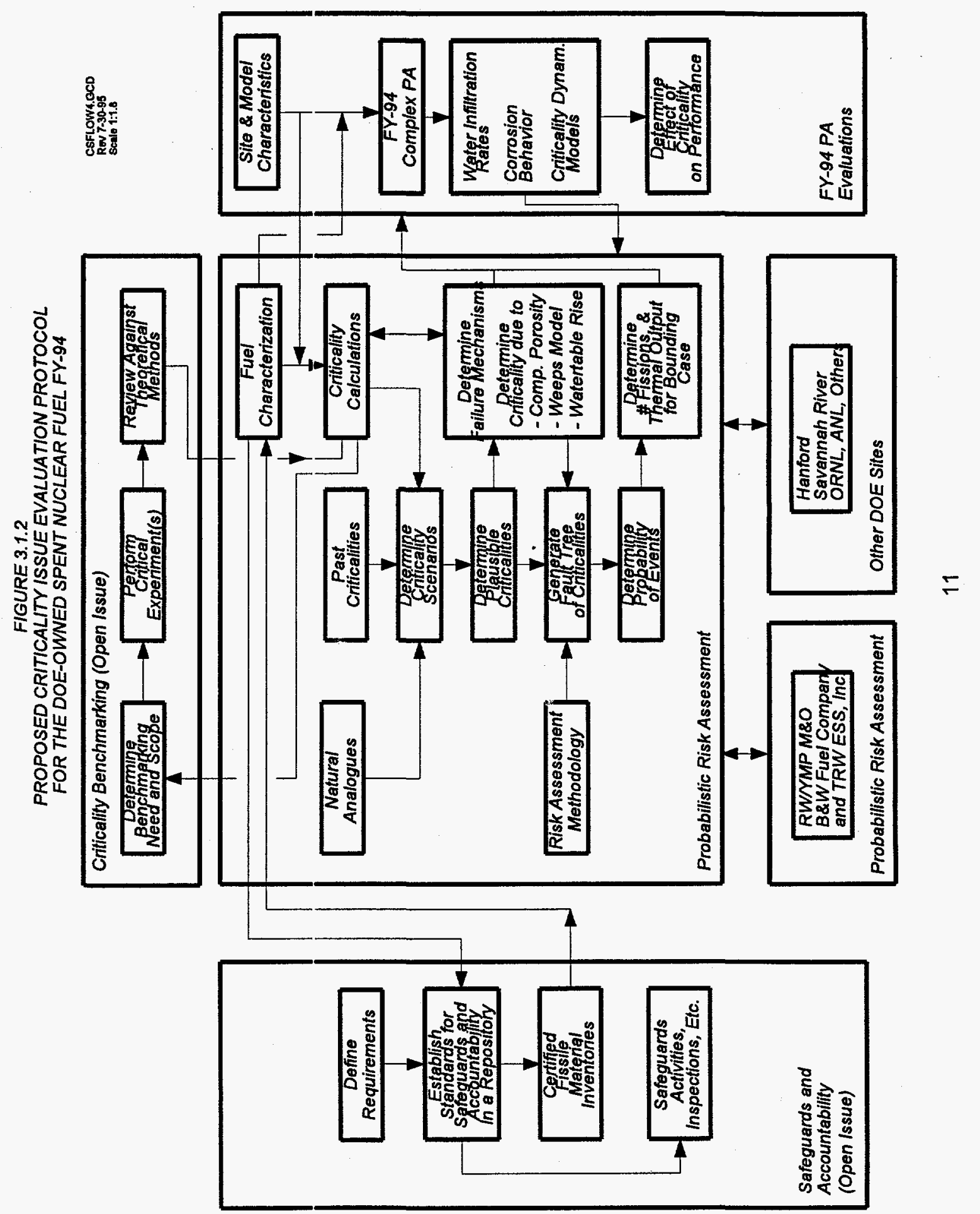


Briefly, the DOE-Owned SNF Program approach to criticality evaluation may be described as follows:

The mechanisms and frequencies for criticality were determined using a fault tree. The advantages of the fault tree are reviewability, ease of making changes, and relatively low cost, in comparison to the PA approach.

All criticality scenarios in the fault tree required a worldwide climate change to a glacial age wherein the excess moisture needed to create the polar icepacks also created a wetter environment in the vicinity of the proposed repository. Even this is not sufficient to cause a criticality, without one of the following: 1) interconnected faults above the repository that concentrate groundwater flow into the repository, 2) local damming, or 3) water table rise.

The major categories of criticality investigated were: water-moderated criticality with either a fast or slow reactivity insertion rate; dry (hard-spectrum) criticality with a fast or slow reactivity insertion rate; water-moderated criticality on the surface due to human intrusion; and farfield criticality. The following is a summary of actions taken with regard to each criticality scenario:

1) Rapid insertion rates could result from gravity collapse of the fuel into a more reactive configuration. However, due to the presence of boron in the stainless steel supporting the fuel, at the point of collapse sufficient boron was assumed to be present to prevent a criticality (i.e., further leaching within the collapsed rubble, or shifting of the rubble, would have to occur, implying a slow approach to criticality).

2) Dry (hard-spectrum) criticality was assumed to have lower energy release than wet criticality because of the lower stable power level of an air-cooled system, and the inherent instability (i.e., the tendency of even small increases of $k_{\text {eff }}$ to lead to disassembly).

3) A farfield criticality (a criticality involving water-borne migration and redeposition of fissile material at a site far away from the waste container), was dismissed. Such a criticality would require large amounts of water to compromise the waste container, break down the fuel cladding and dissolve the uranium (which has very low solubility). This high water flow would tend to spread the uranium over a much larger area than the waste container. Then, localized redeposition would have to occur. Criticality in the waste container was more credible, because the conditions necessary for criticality (loss of structure and boron) already exist, without the additional mechanisms of dissolving uranium, reconcentrating and redeposition.

4) A criticality on the surface, caused by drilling into a waste container, was also dismissed on the basis of being much less likely than the analyzed scenarios. The reasoning was as follows:

a) If the human intrusion happens while sufficient boron remains to keep the waste container subcritical, this borated stainless steel would be intermixed with the fissile material brought to the surface, and wherever the fissile material collects, the boron would also, keeping the composite subcritical. 
b) If the human intrusion occurs after the borated stainless steel has corroded away, the fuel rods would probably be well corroded as well, resulting in a criticality in the waste container. In addition, any of this slumped fissile material brought up in the drilling mud would be even more likely to be dispersed than in the waste container, and less likely to reconfigure into a critical mass.

5) Also investigated were positive feedback mechanisms that could cause the criticality to sustain itself (i.e., a runaway reaction.) Positive feedback scenarios, such as the positive void coefficient for borated water and silica moderation, were dismissed, based upon the following:

a) The main feedback mechanism will be temperature based, and negative (i.e., will tend to shut down neutron activity). Even simple criticality is difficult to achieve.

b) If borated water were present, a positive void coefficient could result upon loss of the water. But, if boron were present in the water, criticality would be even less likely than with straight water. And, with the water removed, the loss of moderator would make the mixture further under moderated, more than compensating for the loss of boron in the water (boron concentration in the water would be low due to the low solubility of the stainless steel matrix).

c) Silica moderation could also potentially have a positive void or temperature coefficient, leading to greater neutron activity. However, this requires several unlikely events, in addition to an in-place criticality, resulting in a much lower probability which was therefore dismissed. This scenario will undergo further review in the future.

The frequency of a criticality in the proposed repository was about $3 \times 10^{-7} /$ year ( $F^{\prime}-94$ study), resulting in a probability of $3 \times 10^{-3}$ of a criticality occurring in the 10,000 -year period.

The most likely criticality would be a moderated "slow cooker" with a slow approach to criticality. Such a criticality would generate no more than $9 \times 10^{24}$ fissions (corre:sponding to $3.7 \mathrm{~kg}^{235} \mathrm{U}$ ) over 10,000 years, if conditions were present to maintain it continuously, which is unlikely. Even this continuous criticality would result in a source term increase of less than $1 \%$ of the fission products already present in the fuel.

\subsubsection{1995 Update of Fault Trees}

In response to review comments on the 1994 PA, the fault trees were updated in 1995 (Appendix D). In the 1994 Performance Assessment, the prisbability of a criticality in a 10,000 year period was $3 \times 10^{-3}$. This number is now $5 \times 10^{-4}$. This reduction by about an order of magnitude is a result of the following changes: 
1). The predominant driver for criticality in the repository is major climatic change (glacial conditions). In the original fault tree, this common event was modeled by different names (e.g., WEEPSDAM-1, FAULTI, WATERTABLE-I, FAULT-1). The fault tree code treated these as independent events, although they incorporate a common event. In the updated tree, additional detail has been modeled so that this commonality can be recognized by the computer code.

2). The original tree did not take into account the minimum times required for failure. For example, if glacial conditions occurred in the 10,000 year interval, the average time for occurrence would be halfway through, at 5,000 years. In addition, the repository does not see water as soon as glacial conditions occur at the surface; the added moisture would still take 2,000 to 3,000 years to infiltrate to the repository level, except in the case of human intrusion. Lastly, the waste canister does not corrode as soon as it becomes wet. Corrosion experts (Dave Stahl, Bill Halsey). indicated that, within our ability to predict, canister failure will require 200 to 20,000 years, depending upon the surrounding environment and water chemistry. But, it is unlikely for water to infiltrate into the repository before 7,000 to 8,000 years after closure, leaving only 2,000 to 3,000 years to corrode through the waste canister before the end of the 10,000 years. Assuming a uniform distribution for the 200-20,000 year corrosion life of the canister means $1800-2800$ years of this distribution lies in the 10,000 -year interval. This yields a probability of canister leak ranging from $0.09-0.14(1800 / 19,800$ to $2800 / 19,800)$.

3). The distributions for corrosion life and frequency of glacial conditions were switched from lognormal to uniform. The justification for this is the absence of a central tendency in both of these distributions.

4). Both single criticality and multiple criticality are modeled in the tree. In several places, an additional event, MULTICRIT, has been added, having a probability of 0.1 . This reflects the belief that the multiple criticalities will happen less often than a single criticality. In the original tree, the multiple criticality branch contributed $1 / 3$ of the overall probability. However, due to the redundancy discussed in item 1 above, the additional effect of this change is small.

The updated fault tree (Appendix D) incorporates the changes described above. The frequency at the top of the tree is in units of "/yr", but many of the events in the tree are developed for a 10,000 year time frame. Therefore, the top event must be multiplied by 10,000 years to get a consistent expression. The result is a unitless probability for a criticality event in the 10,000 year period. This event may be a single criticality or multiple criticality. The lower branches of the tree, under "Multiple Disposal-Container Criticality", will indicate the number of criticalities involved (e.g., the size of the source term). 
The fcllowing are additional mechanisms that others have suggested, but have not been implemented in the updated fault trees. The mechanisms and justification for exclusion are as follows:

1). In the 1994 Performance Assessment, over $10 \%$ of the canisters were projected as failing within 300 years, without an increase in water infiltration (e.g., in the absence of glacial conditions). This was based upon over $50 \%$ of the canisters being in significant contact with the tuff (due to spalling from the heat-affected ceiling or collapse of the railcar support) and the levels of pore water in the existing repository tuff. We feel additional research needs to be conducted to validate this scenario, in the areas af fluid travel, water retention in the resulting corrosion products, and sacrificial behavior of the carbon steel overpack.

2). Bowman and Venneri created a significant controversy by proposing explosive autocatalytic silica-moderated criticalities in the repository. This entire subject involves such a broad range of the sciences, a refutation would be beyond the scope of this report. BowmanNenneri appear to have little support from their peers. The consensus at INEL is that a weakness in the work is in getting to that configuration from the potential environment in the repository. Autocatalytic reactions are very small probability events, and those that might credibly occur must be assembled incrementally (limited by solubilities of uranium in water), limiting the reaction to subexplosive magnitudes.

3). TRW's work with LEU results in criticality frequencies a few orders of magnitude less than ours. One reason for this is the division of their work into two extremes: a highly conservative approach (no credit taken for canister), and an optimistic estimate of the probability of criticality. A more credible upper bound lies between these two estimates, and the reader should be given more guidance on approximately where the "best estimate" lies. For example, stress-corrosion cracking could be included in their model as a mechanism for removing boron poison from the fuel in a collapsed matrix. In addition, LEU differs significantly from HEU with a higher heat source (extending canister life by reducing aqueous corrosivity) and with less reactive concentrations of uranium. Lastly, TRW has not investigated all potential mechanisms yet, putting off farfield criticality and human intrusion to a later date.

4). The original fault trees estimated the frequency of a $230-\mathrm{m}$ rise in the water table as $1 \times 10^{-7} / \mathrm{yr}$. Since that estimate was made, a study came out addressing this water table rise in greater detail.[Ref. 7] Because of the low frequency already postulated for this event, this study did not serve to dismiss that frequency, but confirm it. However, this event was dismissed from the fault tree because of the implied assumption of repeatability in applying this historical geological data to the future. The geological record portrays great inland lakes or 
seabeds being emptied and rising thousands of feet due to plate tectonics. We do not feel that such phenomena will be witnessed again, within the same timeframe as it has occurred in the past. In addition, even if we subscribed to the assumption of repeatability of these events, the resulting frequency is only a fraction of that estimated for flooding of the repository due to a return to glacial conditions at the surface.

\subsection{Criticality Protocol for DOE-Owned SNF}

The following issues need to be resolved for the next step in the protocol:

\subsubsection{Protocol for Resolving Criticality Issues}

It is expected that unforeseen changes will be identified prior to repository closure, resulting in revisions to the fuel inventory and perhaps entirely different types of fuel. Other changes that could occur include new scenarios (e.g., Simoderated, autocatalysis, high mechanical force, greater percentages of mobile .... biologically hazardous fission products, questions regarding whether the "slow cooker" is really bounding), and new parameters (e.g., new mechanisms for corrosion, change in glacial frequencies, new diffusion coefficients for Yucca Mtn area). In addition, various organizations have taken different approaches to criticality work according to their distinct charters and needs. The fact that spent fuel and waste will go to the same repository means that eventually differences in approach will have to be resolved. The existing structure of the RW/EM steering group provides a method for dealing with criticality issues. The repository task team in particular is appropriate for this task. In order to prevent duplication of expense, it would be desirable to use existing criticality studies as a base from which to evaluate changes that arise. Proceeding from this perspective, we propose the following protocol for dealing with unforeseen changes and resolving issues.

The criticality issue resolution protocol (Figure 3.2.1.1) shows the joint EM and OCRWM oversight of the steering group and repository task team. It also shows the parent organizations as the source of information for package, contents, site, model, etc.

Issues may be raised by anyone, but organizations currently involved in criticality analysis would be in the best position to identify new issues. The risk of a criticality is greater with high enriched uranium (HEU) than with low enriched uranium (LEU). Therefore, unresolved issues regarding enrichment may be identified, and this distinction is included in the accompanying example diagram.

Beyond the point of assigning task responsibility only the INEL path is shown in detail. The Yucca Mt office would determine a similar path appropriate for tasks assigned to them.

The nature of an issue would determine the responsible party. For instance, the INEL would address HEU issues while the Yucca Mountain criticality department would handle LEU issues. Failure mechanisms and event probabilities would be determined, and the fault trees would be revised accordingly after the indicated review process. The nature of the corresponding criticality would be evaluated to see if it was already covered by existing models (i.e. slow cooker). The magnitude of effects would be estimated. Those projecting an increase of less than $10 \%$ over current results would be dismissed with justification. For those 
Figure 3.2.1.1 CRITICALITY ISSUE RESOLUTION PROTOCOL

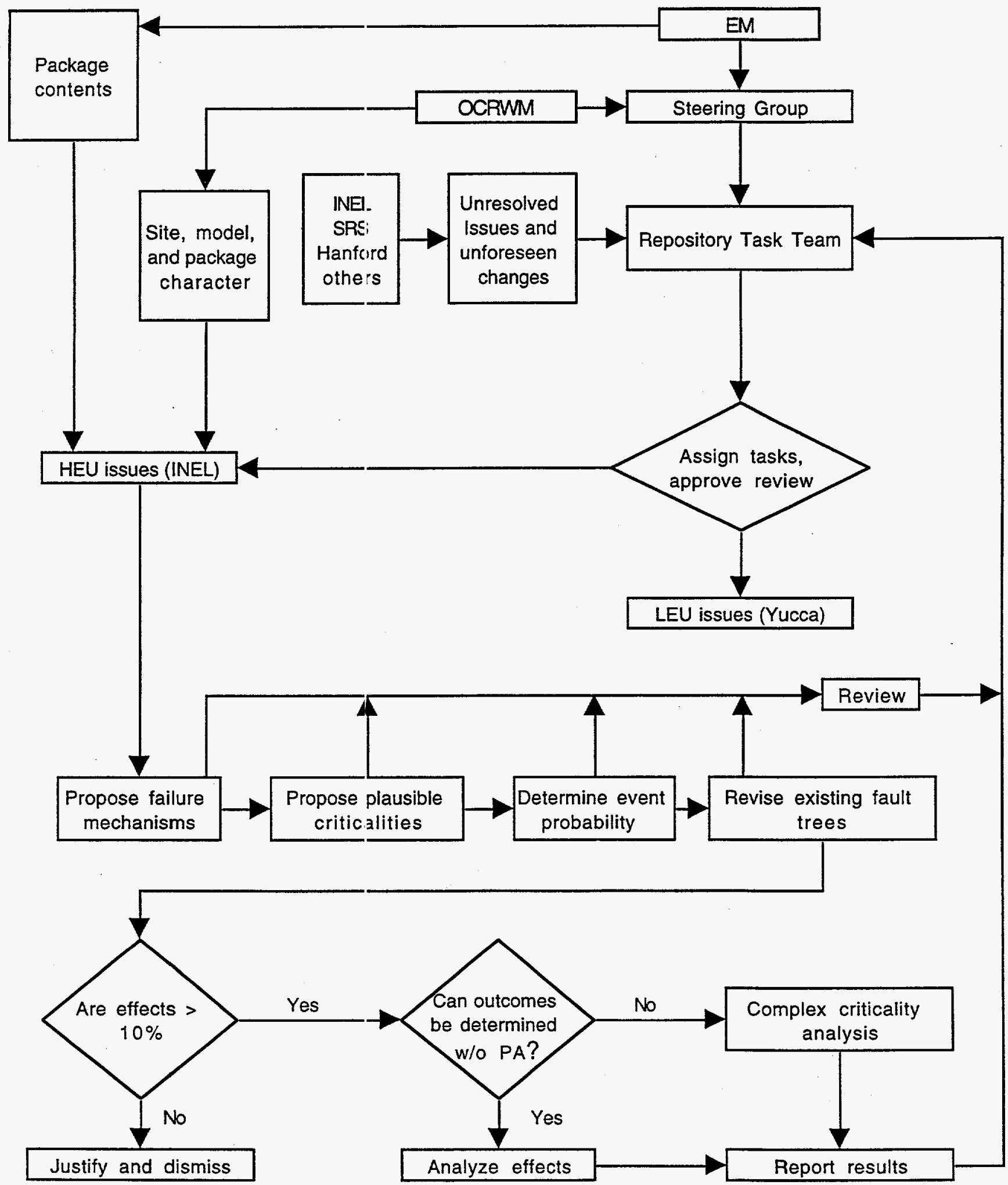


with probability or consequences increasing by more than $10 \%$, a determination would be necessary as to whether the outcomes could be estimated accurately. If they can, the effects would be analyzed and results reported. If not, a more complex criticality evaluation would be required.

The review cycle shown is intended to 'close the loop' in jointly resolving criticality issues that depend on inputs from, or affect, several organizations.

The general approach taken is that no criteria should be based upon the acceptability of criticality in the repository. That is, criticality is considered only as it affects releases according to performance requirements, not as a separate category of events. Other modeling details -- for example, whether vadose zone flow is through cracks or homogeneous regions - is only a means to the end: The accurate estimation of the consequences. In the same way, criticality should not be an issue of itself, only its effect on the consequences. If an autocatalytic event can occur (which may be construed by the public as an explosion), we should only be concerned about the heightened consequences that may result from that event, not the fact that an autocatalytic event occurred. In conclusion, we should address the issue technically and completely, but not compare the frequency of a criticality to a separate acceptability criteria.

\subsubsection{Predicting Repository Behavior}

Predicting repository behavior far into the future is a very controversial topic with inadequate data in many areas. As a result, we expect continuing controversy, particularly in the following areas: Accelerated corrosion due to rockfall, the protective effects of intermixing HEU with LEU (the higher temperature extending the cask life), near-/far-field criticality (silica-moderated criticality, human intrusion, nearfield (i.e., just outside the cask)).

\subsubsection{Determine Acceptable Criteria}

A comparison of our criticality safety approach with 10 CFR 60.131 (b) (7) is in order. That document requires that two unlikely independent events occur before a criticality is possible. All of our accident scenarios identify at least two initiating events, many identify more. However, the presence of water creates dependency between these events. In direct human handling of fuel, similar contingency principles apply. Safety steps may be performed by the same person. If more than one person is involved, they probably work for the same supervisor, so some dependence exists. Any operations involving human activity are likely to have greater chance for error than a sealed repository.

Furthermore, safety analysis in the past has given greater weight to passive measures (reactor containment vessel failure, a single-event failure, is an acceptable risk) than to active ones, and the repository is entirely passive.

Still further, criticality safety in unshielded areas requires triple contingency, while shielded, inhabited areas only require double contingency. Extending the same line of reasoning, we could argue that a repository is at least one step further removed from human contact, and the safety requirements should recognize this. Therefore, we do not feel traditional double contingency criteria apply to the repository. 


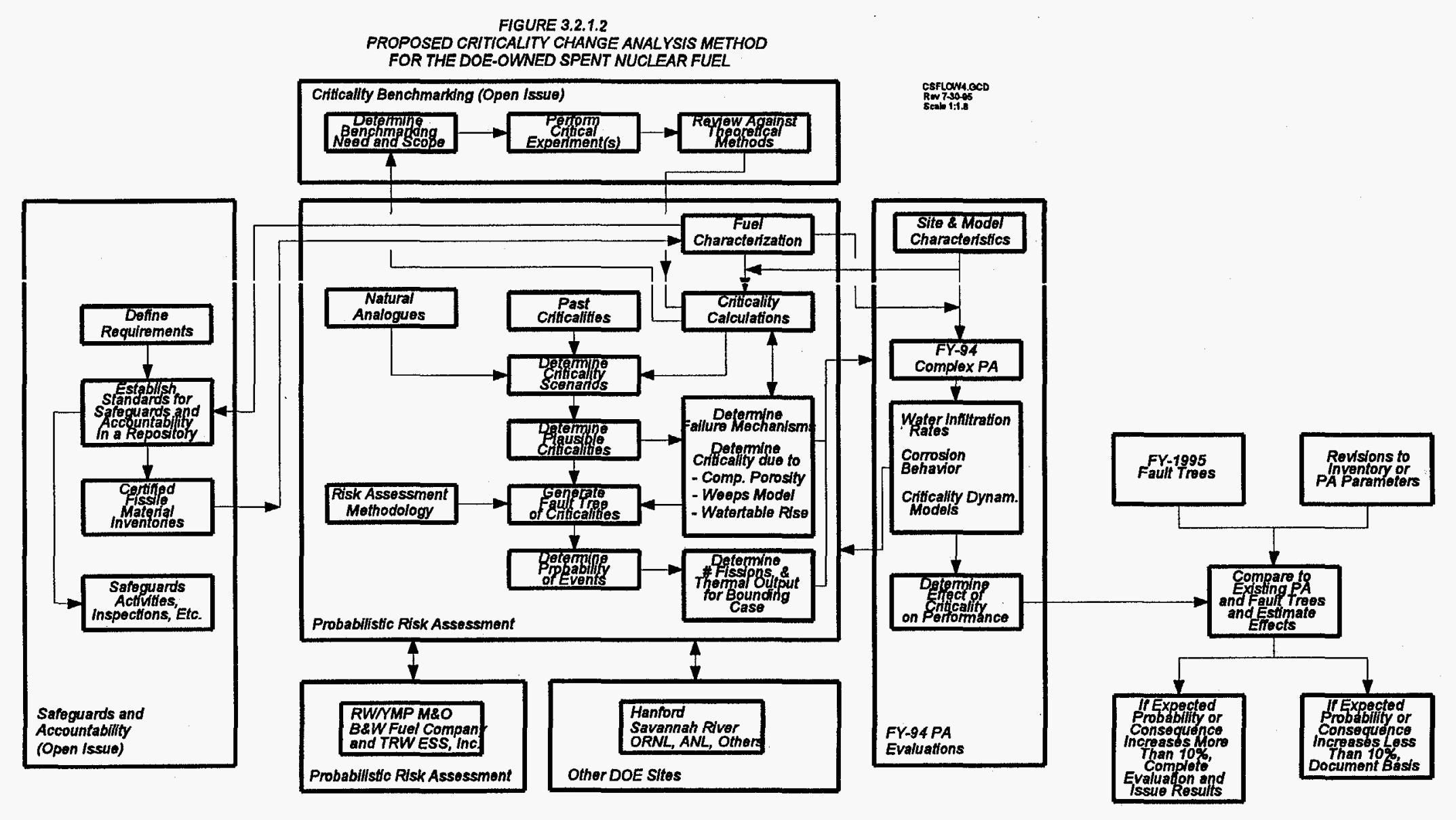




\subsubsection{Assessment Beyond 10,000 Years}

The National Academy of Sciences (NAS) recommended that "...compliance assessment be conducted for the time when the greatest risk occurs, within the limits imposed by long-term stability of the geologic environment."[Ref. 5] "The geologic record suggests that this time frame is on the order of $10^{6}$ years."[Ref. 6]

Our response to this should be that we not go past 10,000 years because:

A) The field of geological dating is one with many controversies -- The NAS issued a report on prehistoric water table rise at the Yucca Mountain Repository. It claims that the most recent volcanic activity in the area was 10-12 million years ago[Ref. 7]. An intervenor has challenged this value with a claim of 30,000 years.[Ref. 8]

The dating of a volcanic eruption on the upper rim of the Grand Canyon (see table) illustrates one of the causes for such controversy; the results vary widely between techniques. Most geologists will claim the appropriate technique is obvious, since the approximate date is known. However, such self-validating assumptions may not be successful in a controversy like the licensing of the Yucca Mountain Repository.

Table 1: Dating of Basaltic Rocks of the Uinkaret Plateau

\begin{tabular}{||l|l|}
\hline Source & Date (years) \\
\hline \hline American Indian Legend & few thousand \\
\hline $\mathrm{K}-\mathrm{Ar}$ & 10,000 [Ref. 9] \\
\hline Stratigraphic controls & $\begin{array}{l}2.6-117 \pm 3 \\
\text { million[Ref. 10] }\end{array}$ \\
\hline $\mathrm{Rb}-\mathrm{Sr}$ Isochron & $\begin{array}{l}\text { low thousands to a } \\
\text { few million }\end{array}$ \\
\hline $\mathrm{Pb}-\mathrm{Pb}$ Isochron & $\begin{array}{l}1.34 \pm 0.04 \\
\text { billion[Ref. 11] }\end{array}$ \\
\hline
\end{tabular}

B) Actual Risk is Small -- To this point, the risks of buried waste and fuel have been treated in isolation from any other events. This may be appropriate for an academic exercise, but not for the support of a project that will eventually require public acceptance. The more we can do to compare repository risks to familiar or existing risks, the better chance we will have of completing the repository. 
After 300 yearsi, the risk from buried nuclear waste is less than the risk from the original ore the fissile material was derived from. This comparison is quite conservative, rot allowing for the fact that the original ore was randomly distributed with regard to water tables and human habitations, and the repository is designed to ve in a dry, stable and unpopulated area.

EPA regulations already require that a repository be made 10 times safer than the original ore bolly.[Ref. 13] If other acceptance criteria continue this restrictive trend, the repository could be "viewed as a means of remediation of the effects of natural ore boclies."[Ref. 14]

C) Maintaininc a Low Profile -- It has been said that the average life of a geological dating controversy is 10 years.[Ref. 15] The Yucca Mountain licensing cannot stand such a delay, especially since it can be avoided early on by setting reasonable crileria.

By going beyond 10,000 years, we give credibility to the "need" to do so. 
1 References:

3 1. Stratton, William R., revised by Davis R. Smith, " A Review of Criticality Accidents", DOE/NCT-04 (March, 1989)

2. 40 CFR 191 Appendix C to Part 191- Guidance for Implementation to Subpart B. This appendix states that "...the performance assessments need not consider categories of events and process that are estimated to have less than one chance in 10,000 of occurring over 10,000 years."

3. Committee on International Security and Arms Control, National Academy of Sciences, "Management and Disposition of Excess Weapons Plutonium," National Academy Press, Washington, D.C.

4. C.D. Bowman and F. Venneri, "Underground Supercriticality from Plutonium and Other Fissile Material," LA-UR94-4022A, Los Alamos National laboratory, Los Alamos, NM (Undated)

5. NAS, Technical Bases for Yucca Mountain Standards, National Research Council, pp. 6-7.

6. Ibid, p. 9.

7. Panel on Coupled Hydrologic/Tectonic/Hydrothermal Systems at Yucca Mountain, Ground Water at Yucca Mountain. How High Can it Rise? National Research Council, National Academy Press, 1992.

8. C. B. Archambeau, Review of the NAS/NRC Report: "Groundwater at Yucca Mountain: How High Can it Rise?", Nuclear Waste Project Office, State of Nevada, Special Report \#1, Contract \#92/94.0004, Dec. 1992, p. 4.

9. Reynolds, S. J., et al., "Compilation of Radiometric Age Determinations in Arizona," Arizona Bureau of Geology and Mineral Technology Bulletin 197, 1986, p. 8.

10. Ibid, pp. 14, 16 .

11. Dr. Steve Austin, Editor, Grand Canyon: Monument to Catastrophe, ICR, 1994.

12. C. Alibert, "Isotope and Trace Element Geochemistry of Colorado Plateau Volcanics," Geochimica et Cosmochimica Acta, Vol. 50, 1986, pp. 2735-2750.

13. J. O. Duguid, "Calculations Supporting Evaluation of Potential Environmental Standards for Yucca Mountain," prepared under USDOE contract \#DE-AC01-91RW00134, April 1994. 
14. Ibid.

15. E. Marshall, "Clovis Counterrevolution," Science 279:738-741, August 17, 1990.

2 
Appendix A

The following spreadsheet was developed for a comparison of key isotopes in the inventory. Values in the top section are taken from the summary table in Appendix A of the PA report. Values in the other sections are calculated from those.

\begin{tabular}{|c|c|c|c|c|c|}
\hline \multicolumn{6}{|c|}{ Comparison of inventory isotopes of greatest concern } \\
\hline \multicolumn{6}{|c|}{ curies reported } \\
\hline & PWR & ATR & graphite & N-reacior & Shippingport \\
\hline C-14 & 92.4 & 0.029 & 120.5 & 129.5 & 66.4 \\
\hline Tc-99 & 783 & 3566 & 393 & 2298 & 9661 \\
\hline I-129 & 1.9 & 5.87 & 1.176 & 4.6 & 16.3 \\
\hline U-234 & 212 & 17.9 & 294 & 962 & 83.8 \\
\hline $\mathrm{Np}-237$ & 54 & 72.4 & 8.16 & 52.3 & 198.5 \\
\hline MTHM & 162 & 720 & 28 & 2100 & 110 \\
\hline total curies & $2.07 E+07$ & $4.00 E+07$ & $4.23 E+06$ & $3.00 E+07$ & $1.74 E+08$ \\
\hline \multicolumn{6}{|c|}{ curies per MTHM } \\
\hline C-14 & 0.57 & 0.00004 & 4.3 & 0.062 & 0.60 \\
\hline Tc-99 & 4.8 & 4.95 & 14. & 1.1 & 88 \\
\hline $1-129$ & 0.01 & 0.008 & 0.042 & 0.002 & 0.15 \\
\hline U-234 & 1.3 & 0.025 & 10.5 & 0.46 & 0.76 \\
\hline Np-237 & 0.33 & 0.1 & 0.29 & 0.025 & 1.8 \\
\hline \multicolumn{6}{|c|}{ Ratio of curies to total curies } \\
\hline C-14 & $4.5 \mathrm{E}-06$ & $7.25 \mathrm{E}-10$ & $2.8 \mathrm{E}-05$ & $4.3 \mathrm{E}-06$ & $3.8 \mathrm{E}-07$ \\
\hline Tc-99 & $3.8 \mathrm{E}-05$ & 0.00009 & $9.3 \mathrm{E}-05$ & 0.00008 & $5.5 \mathrm{E}-05$ \\
\hline I-129 & $9.2 E-08$ & $1.5 \mathrm{E}-07$ & $2.8 \mathrm{E}-07$ & $1.5 \mathrm{E}-07$ & $9.3 E-08$ \\
\hline U-234 & $1.0 \mathrm{E}-05$ & $4.5 \mathrm{E}-07$ & $7.0 \mathrm{E}-05$ & 3.2E-05 & $4.8 \mathrm{E}-07$ \\
\hline Np-237 & 2.6E-06 & 0.000002 & $1.9 \mathrm{E}-06$ & 1.7E-06 & $1.1 \mathrm{E}-06$ \\
\hline
\end{tabular}




\begin{tabular}{|c|c|c|c|c|c|c|c|c|c|c|c|c|c|c|}
\hline & \multicolumn{2}{|c|}{ ISOTOPE COMPARISON } & & \multirow[b]{2}{*}{ DOE SNFCi } & \multirow{3}{*}{ N-react } & \multirow[b]{3}{*}{ Shipport } & \multirow[b]{3}{*}{ ATR } & \multirow[b]{3}{*}{ Comm } & \multirow[b]{2}{*}{ DOE Waste } & & \multirow[b]{3}{*}{ Hanford } & \multirow[b]{3}{*}{ INEL } & \multirow[b]{2}{*}{ DOE Total } & \multirow[b]{2}{*}{ DOE/Yucca } \\
\hline & TSPA Sandia & & & & & & & & & & & & & \\
\hline isotope & Yuc mean Ci/MT & Yuc tot MTHM & Total Yucca Ci & Graphite & & & & & West Valley & SAS & & & & \\
\hline C-14 & 1.45 & 63000 & 91350 & 121 & 130 & 66 & 0.03 & 92 & & & & & 409.03 & 0.004 \\
\hline$S \theta-79$ & 0.453 & 63000 & 28539 & 16 & 69 & 288 & 106 & 24.5 & 3.5 & 1350 & 7.6 & & 1864.60 & 0.065 \\
\hline Tc-99 & 14.3 & 63000 & 900900 & 393 & 2298 & 9661 & 3566 & 783 & 109 & 20600 & 18330 & 3359 & 59099.00 & 0.066 \\
\hline $1-129$ & 0.0339 & 63000 & 2135.7 & 1.2 & 4.6 & 16 & 5.9 & 2 & & & 0.03 & & 29.73 & 0.014 \\
\hline $\mathrm{Pa}-231$ & $3.70 \mathrm{E}-05$ & 63000 & 2.331 & 10.6 & 0.0072 & 0.03 & 0.025 & 0.004 & 15 & & & & 25.67 & 11.011 \\
\hline U-233 & 5.77E-05 & 63000 & 3.6351 & 2305 & 0.0048 & 0.026 & 0.0157 & 0.0091 & 9.7 & 0.0084 & & & 2314.76 & 636.781 \\
\hline U-234 & 1.51 & 63000 & 95130 & 294 & 962 & 84 & 18 & 212 & 4.2 & 223 & 9.4 & 388 & 2194.60 & 0.023 \\
\hline U-235 & 0.0228 & 63000 & 1436.4 & 1.4 & 32.8 & 75.6 & 66 & 2.8 & 0.097 & 0.831 & 0.386 & & 179.91 & 0.125 \\
\hline U.236 & 0.312 & 63000 & 19656 & 26.8 & 108 & 319 & 121 & 41.7 & 0.3 & 6.24 & 0.93 & & 623.97 & 0.032 \\
\hline U-238 & 0.315 & 63000 & 19845 & 0.0312 & 696 & 15 & 7 & 51.6 & 0.86 & 55.46 & 7.29 & & 833.24 & 0.042 \\
\hline $\mathrm{Np}-237$ & 0.378 & 63000 & 23814 & 8.2 & 52 & 200 & 72 & 54 & 23.4 & 420 & 390 & 87 & 1306.60 & 0.055 \\
\hline Pu-239 & 333 & 63000 & 20979000 & 114 & $2.10 E+05$ & $2.30 \mathrm{E}+04$ & $5.90 \mathrm{E}+05$ & $5.10 E+04$ & 1757 & $6.80 E+04$ & 2763 & & 946634.00 & 0.045 \\
\hline & & & & & & & & & & & & & & \\
\hline & & & & & & . & & & & & & & & \\
\hline & INTERA & & & & & & & & & & & & & \\
\hline isotope & Yuc mean $\mathrm{Ci} / \mathrm{MT}$ & Yuc tot MTHM & Total Yucca Ci & Graphite & N-react & Shipport & ATR & Comm & West Valley & SPS & Hanford & INEL & & \\
\hline C- 14 & 1.48 & 63000 & 93240 & 121 & 130 & 66 & 0.03 & 92 & & & & & 409.03 & 0.004 \\
\hline Se-79 & 0.48 & 63000 & 30240 & 16 & 69 & 288 & 106 & 24.5 & 3.5 & 1350 & 7.6 & & 1864.60 & 0.062 \\
\hline TC-99 & 15.1 & 63000 & 951300 & 393 & 2298 & 9661 & 3566 & 783 & 109 & 20600 & 18330 & 3359 & 59099.00 & 0.062 \\
\hline $1-129$ & 0.0372 & 63000 & 2343.6 & 1.2 & 4.6 & 16 & 5.9 & 2 & & & 0.03 & & 29.73 & 0.013 \\
\hline $\mathrm{Pa}-231$ & $3.59 \mathrm{E}-05$ & 63000 & 2.2617 & 10.6 & 0.0072 & 0.03 & 0.025 & 0.004 & 15 & & & & 25.67 & 11.348 \\
\hline U-233 & $7.82 E-05$ & 63000 & 4.9266 & 2305 & 0.0048 & 0.026 & 0.0157 & 0.0091 & 9.7 & 0.0084 & & & 2314.76 & 469.850 \\
\hline$U-234$ & 1.43 & 63000 & 90090 & 294 & 962 & 84 & 18 & 212 & 4.2 & 223 & 9.4 & 388 & 2194.60 & 0.024 \\
\hline U-235 & 0.0168 & 63000 & 1058.4 & 1.4 & 32.8 & 75.6 & 66 & 2.8 & 0.097 & 0.831 & 0.386 & & 179.91 & 0.170 \\
\hline U-236 & 0.293 & 63000 & 18459 & 26.8 & 108 & 319 & 121 & 41.7 & 0.3 & 6.24 & 0.93 & & 623.97 & 0.034 \\
\hline U.238 & 0.314 & 63000 & 19782 & 0.0312 & 696 & 15 & 7 & 51.6 & 0.86 & 55.46 & 7.29 & & 833.24 & 0.042 \\
\hline Np-237 & 0.487 & 63000 & 30681 & 8.2 & 52 & 200 & 72 & 54 & 23.4 & 420 & 390 & 87 & 1306.60 & 0.043 \\
\hline Pu-239 & 375 & 63000 & 23625000 & 114 & $2.10 \mathrm{E}+05$ & $2.30 \mathrm{E}+04$ & $5.90 E+05$ & $5.10 E+04$ & 1757 & $6.80 E+04$ & 2763 & & 946634.00 & 0.040 \\
\hline
\end{tabular}




\title{
Appendix $\mathrm{C}$
}

\section{Review of Various Positions On Silica Moderated Criticality}

\author{
Los Alamos National Laboratory Internal Review
}

The first draft of the Bowman/Nenneri paper entitled "Nuclear Excursions and Eruptions from Plutonium and Other Fissile Material Stored Underground" appeared around November 1994. The authors planned to present the paper at the December American Nuclear Society (ANS) meeting on DOE Spent Nuclear Fuel- Challenges \& Initiatives. However, the LANL management decided to conduct an internal review of the paper prior to releasing it for formal publication. Three teams (red, white and blue) were assigned to evaluate the draft paper. The following are examples of their findings.

\section{Red Team}

"The analysis makes far too many upper limit over simplifications and omissions, including too much Pu concentration in the glass, Pu and rock compositions with no other neutron absorbers, no consideration of the impact of self-sealing clays on material migrations, too high rock strength to unduly confine energy generation, and geologic and vaporization uniform Pu dispersal mechanisms that are not physically possible. Every assumption errs in a direction to promote the authors conclusions."

\section{White Team}

"The review concluded that the probability of each of these steps (the steps are dispersal of the Pu could increase its reactivity to the point where criticality, auto-catalytic reaction, and explosive energy could occur) is vanishing small and that the probability of the occurrence of all three is essentially zero. Moreover, even if these steps could occur, any energy release would be too small and slow to produce any significant consequences either in the repository or on the surface.

.... We disagree with the paper's major assumptions and find its major conclusions to be incorrect for the fundamental, technical reasons discussed above."

\section{Blue Team}

"The calculations exhibited a tendency to expand and recompress with a period of tens of milliseconds. Recompression did not result in regaining criticality. The calculations did not include the effect of heat conduction. If it were possible for heat to exit the region of criticality, recompression might result in regaining criticalifty, possibly producing additional yield. While this is a long shot, it should be investigated before burying fissile materials, especially plutonium."

As evidence of the above summaries, both the red and white team find the possibility of a silica moderated criticality to be very unlikely and has no merit. However, the blue team did indicated that "While this (the scenario) is 
a long shot, it should be investigated before burying fissile materials, especially plutonium."

In addition to the red, white and blue Team summaries of their evaluation, LANL has also published a position paper which was used by Senator Bennett Johnston on his discussion "Allegations regarding potential nuclear explosions in a geologic repository for Spent Nuclear Fuel" on the Senate floor $\mathrm{cn}$ March 7, 1995. This official comments from LANL were published on the Internet as LAUR-95-0851, comments on "Nuclear Excursions" and "Criticality Issues". It was published after Bowman/Venneri responded to the red, white and blue team review comments through a second draft of their paper "Criticality Issues for Thermally Fissile Materials in Geologic Storage," dated February 1995. The final two paragraphs summarize the position of LAUR-95-0851:

"We do not find any value in these two papers that would, ustify their publication, and do not see how to produce such a paper from them. They contain fundamental errors in concept and execution. They show no grasp of such elementary concepts as the time scale for the approach to criticality, the raile of energy release, and the crucial role of the negative temperature coefficient of the systems treated. Moreover, they show no appreciation of these points even after they were pointed out clearly in the review by those who do did understand them. That is compounded by the shifting scenarios on which the papers are based and the alarmist estimates of potential effectis, which have become less credible and more shrill throughout the revien' process.

The authors have shown little interest in technical suggestions or inclination to respond to them; thus, it would not appear to be useful to continue this one-sided discussion. However, it would be irresponsible for the Laboratory to dissieminate untested opinions in this visible and controversial area. Thus, if this program is continued, and these individuals remain associated with it, the laboratory would be well served by establishing a permanent red team, funded by this program and composed of members from the cognizant technical divisions, with the responsibility of independently checking the calculations done by those in the program."

\section{Westilnghouse Savannah River Company Review}

The W/estinghouse Savannah River Company (WSRC) reviewed the BowmanNenneri papers and published a report: Parks, P.B., Hyder, M.L., and Williamson, T.G. "Final Issue of: Consequences of the Bowman-Venneri Nuclear Excursion Thesis on the Prospects for Placing Vitrified Plutonium Canisiers in Geologic Repositories" (U), PDI-SPP-95-0023, June 5, 1995. SRS sided with Bowman and Venneri with qualifications about their assumiptions and agreed in the sense of recognizing the possibility of a nuclear upset and suggested that further study should be done. The conclusions of the paper follow: This analysis indicates that, with the simpliying assumptions that the geologic media is composed of only light materials with low neutron absorption cross sections, that the boron lithium and iron poisons are removed from the fissile material, that the fissile material forms a critically favorable geometry, and that water intrudes and acts favorably for criticality, criticality could occur in an uniderground storage area in which Pu-239 has been stored in 
glass. These simplifying assumptions may not be realistic and they should be carefully investigated before programmatic conclusions are made. Disposal of defense high level waste in borosilicate glass logs in mined repositories is unaffected by the Bowman-Venneri thesis because the amount of fissile material in these logs is too small to form critical configurations. Disposal of spent commercial reactor fuel underground may also be unaffected by the Bowman- Venneri thesis because of the poisoning effect of U-238. Unless the Bowman-Venneri thesis can be discredited on physical grounds, the DOE must approach the question of geologic disposal of plutonium cautiously. Comparative cost analyses of the various alternatives would have to take into account prevention of the Bowman-Venneri type of criticality excursion. This suggests that the direct disposal of Pu-glass in a mined geologic repository may not appear economically attractive if that is done.

\section{Lawrence Livermore National Laboratory Review}

At the request of their sister laboratory LANL, Lawrence Livermore. National Laboratory (LLNL) also reviewed the BowmanNenneri papers and published a report UCRL-ID-120990 COM titled "Comments on the Draft Paper 'Underground Supercriticality from Plutonium and other Fissile Materials' written by C. D. Bowman and F. Venneri (LANL)" on May 5, 1995. The LLNL report sided with the red and white teams of LANL by stating that "We conclude that the draft paper by Bowman and Venneri has failed to note the important differences among the several fissile-containing materials under consideration for geologic disposal. It has not demonstrated that the hypothetical models used are relevant to the disposal of commercial reactor fuel, which bears little resemblance in composition or configuration to the models it discussed. .... Because of the serious technical errors and deficiencies in the draft paper by Bowman and Venneri, we do not believe it would make a useful contribution to the literature in the field of criticality safety in geologic disposal of fissile materials."

\section{Other Possible Future Reviews}

In a discussion with Mr. Richard Anderson of LANL on May 14, 1995, he indicated that LANL is considering the need to further evaluate the Bowman and Venneri thesis. Thus, future Bowman and Venneri review may be necessary to dismiss the hypothetical scenarios. 
1
2

2
3

4

5

6

7

8

9

- 10

11

12

13

14

15

16

17

Appendix D

FY-1995 Update of Fault Trees 


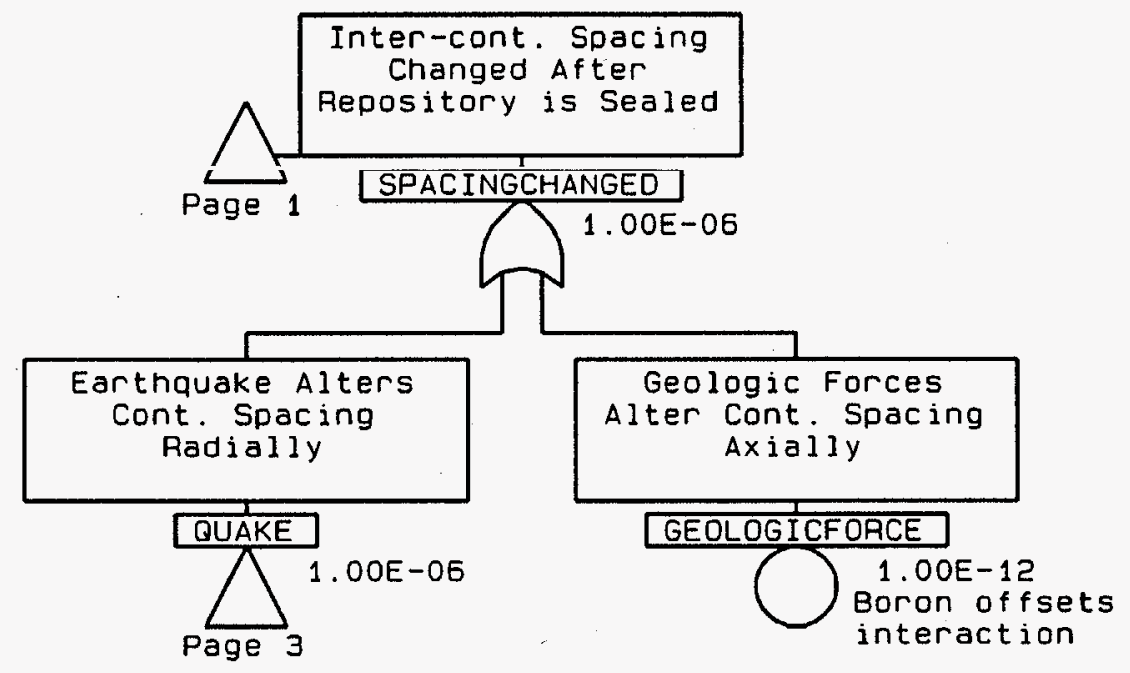

\begin{tabular}{|cc|c|c|c|c|}
\hline Criticality ACCident in HEU Repository & 1 & 2 & 1 & 1 \\
\hline
\end{tabular}



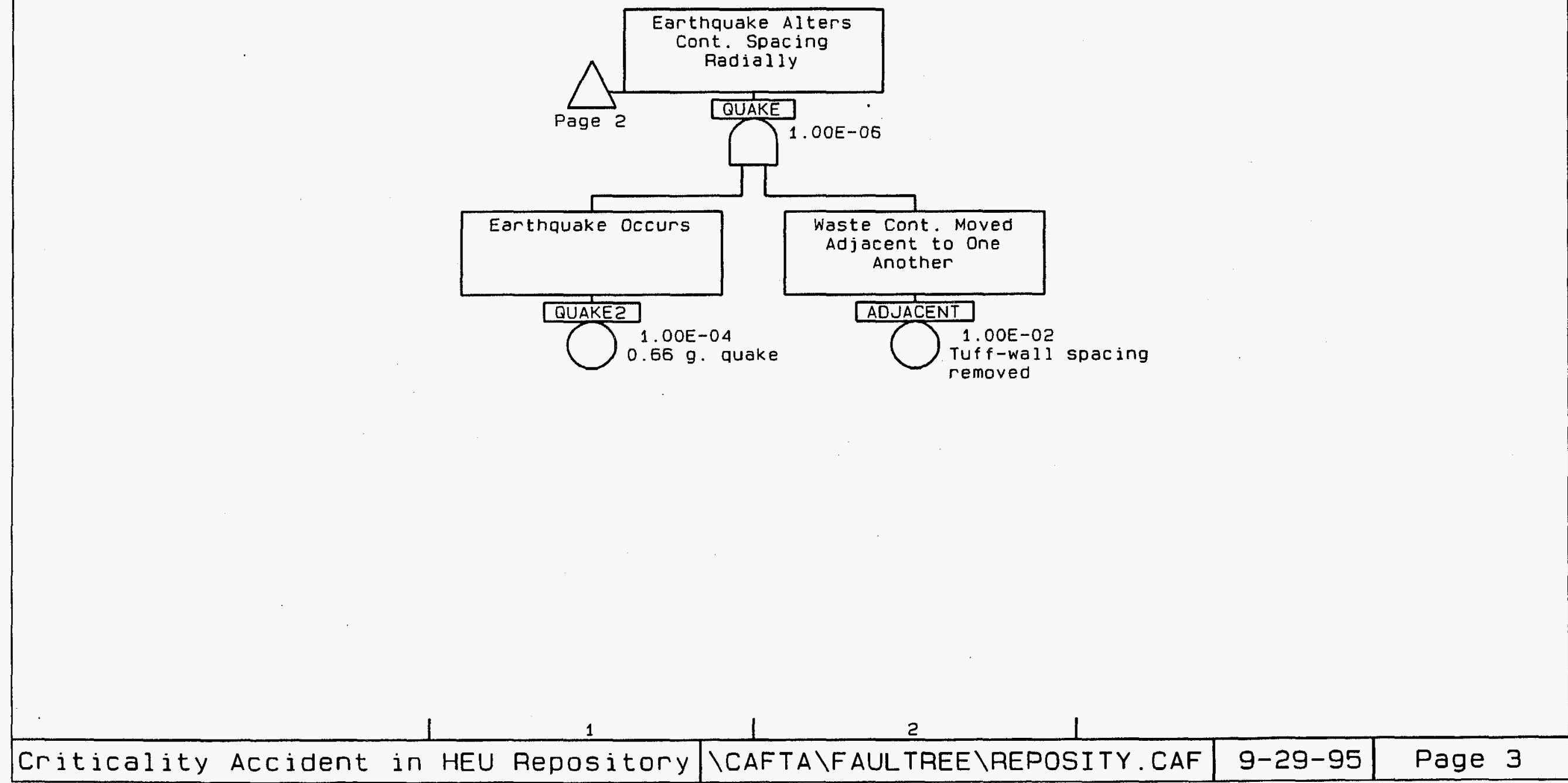


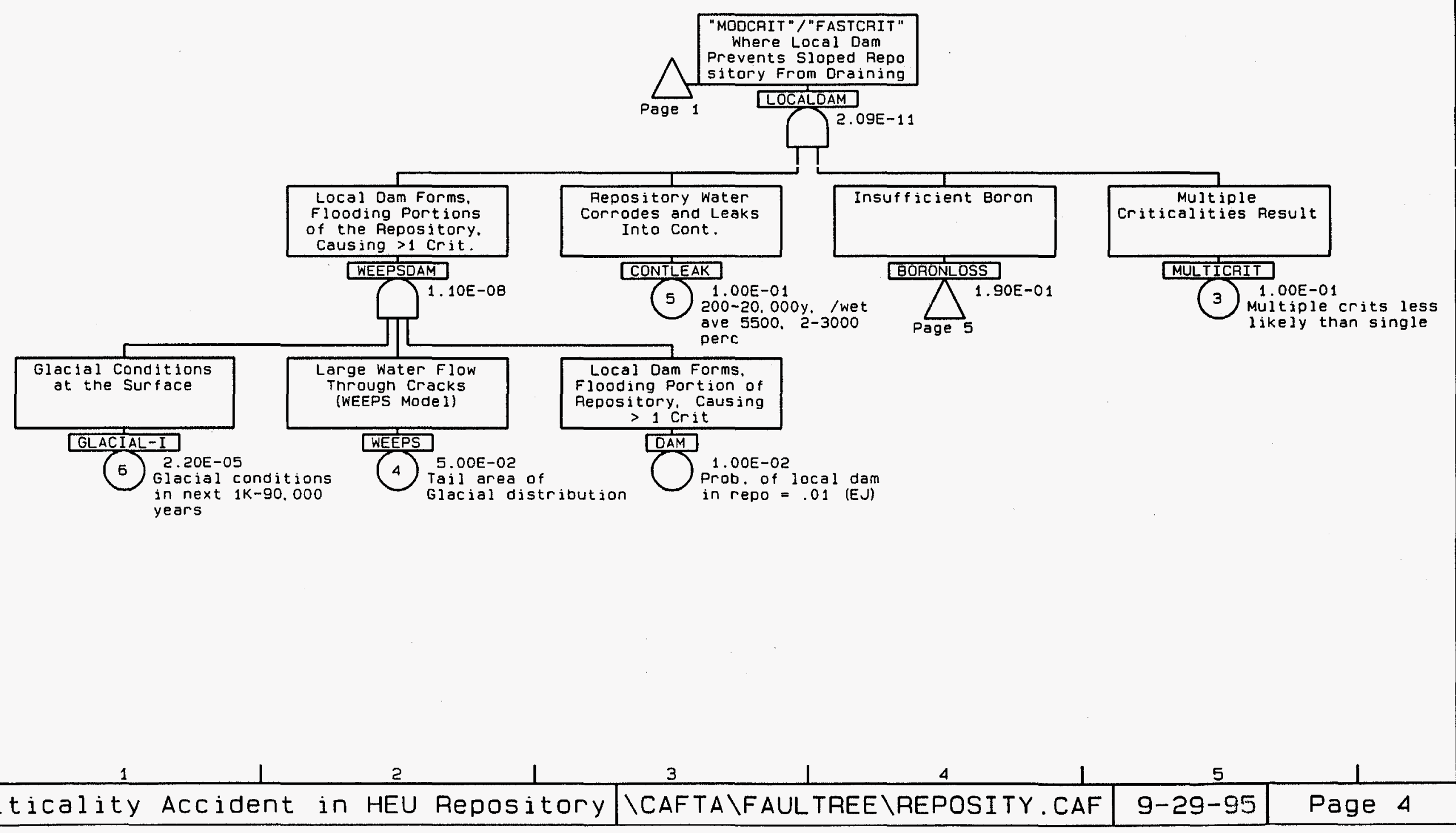




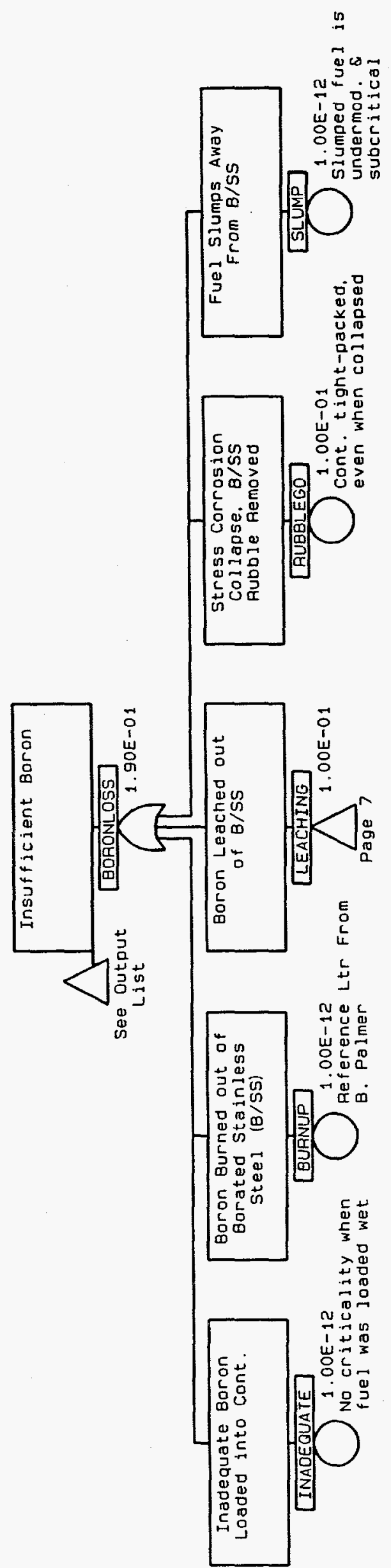




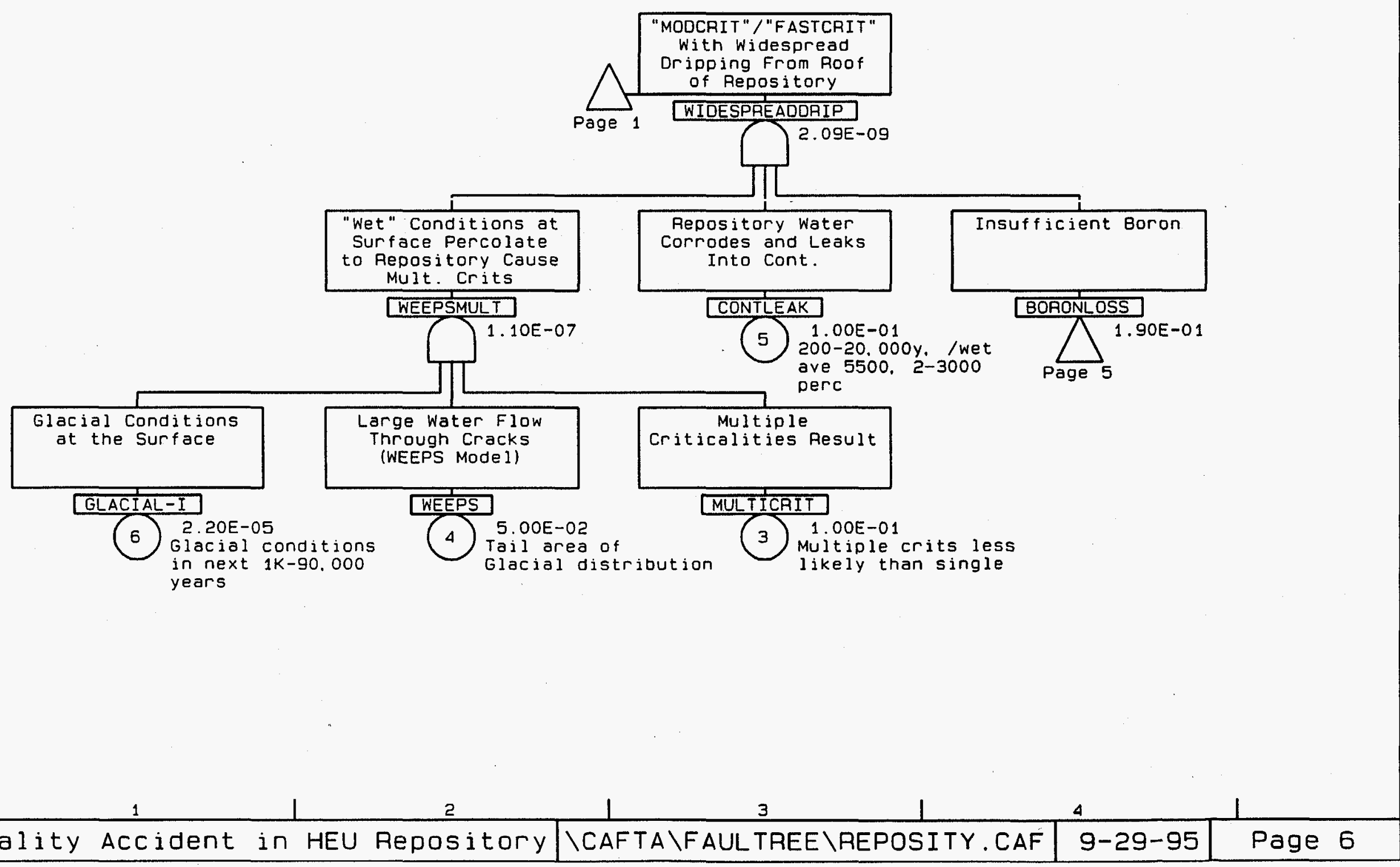




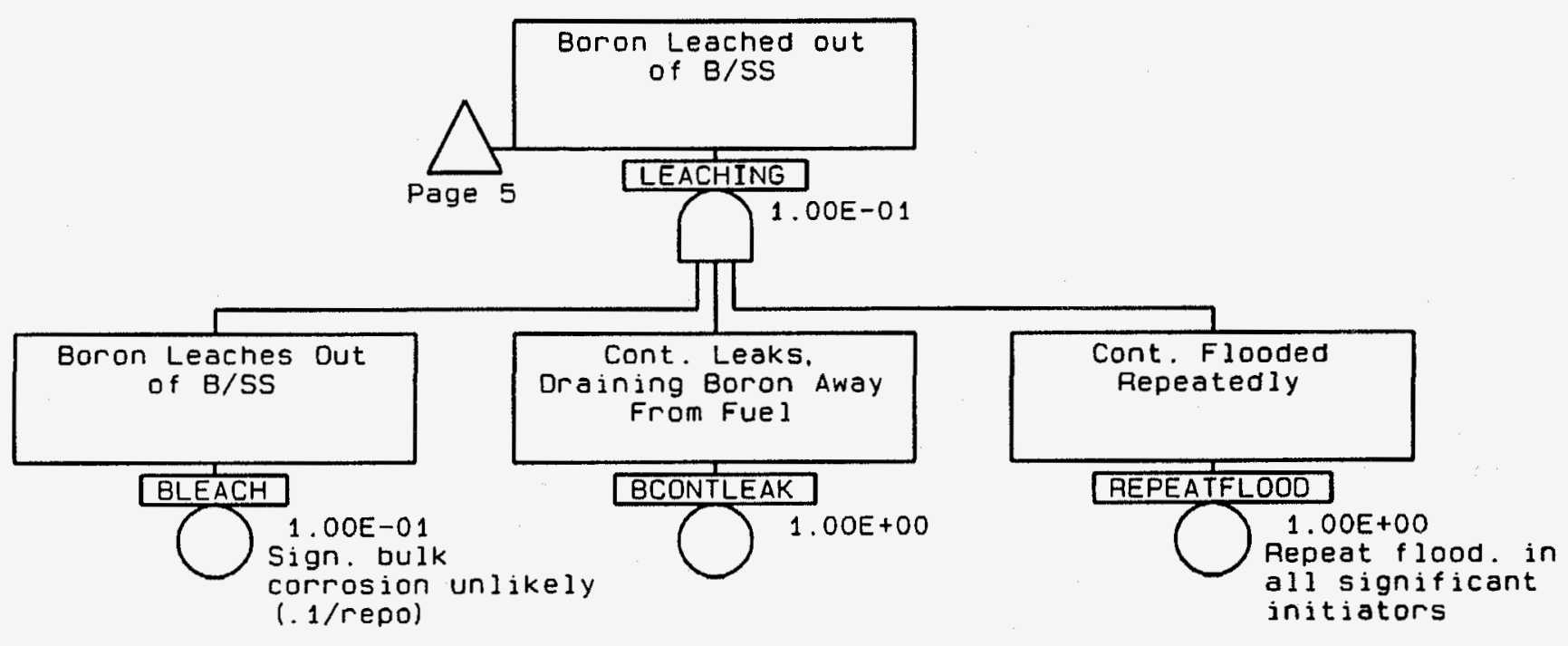

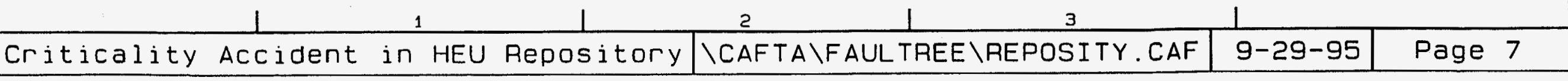




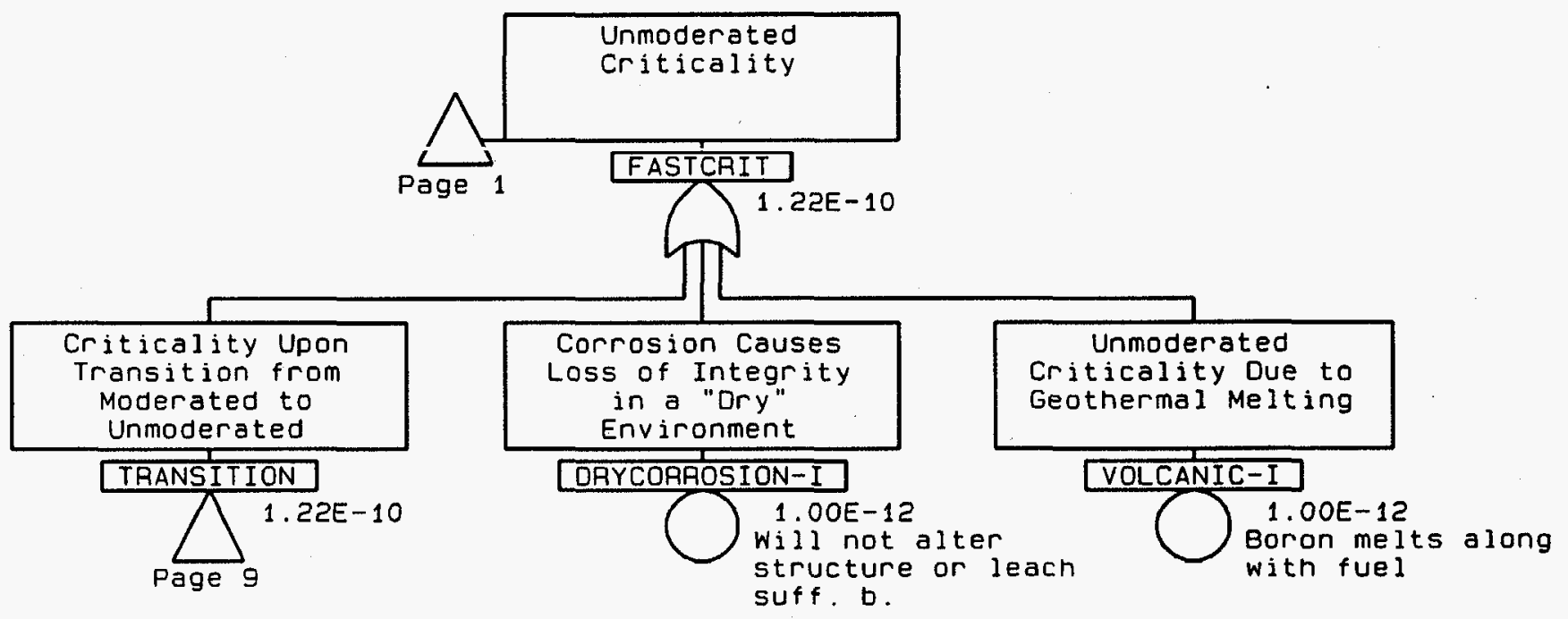

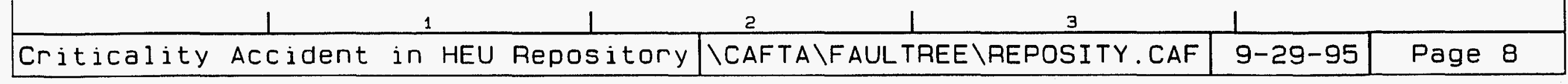




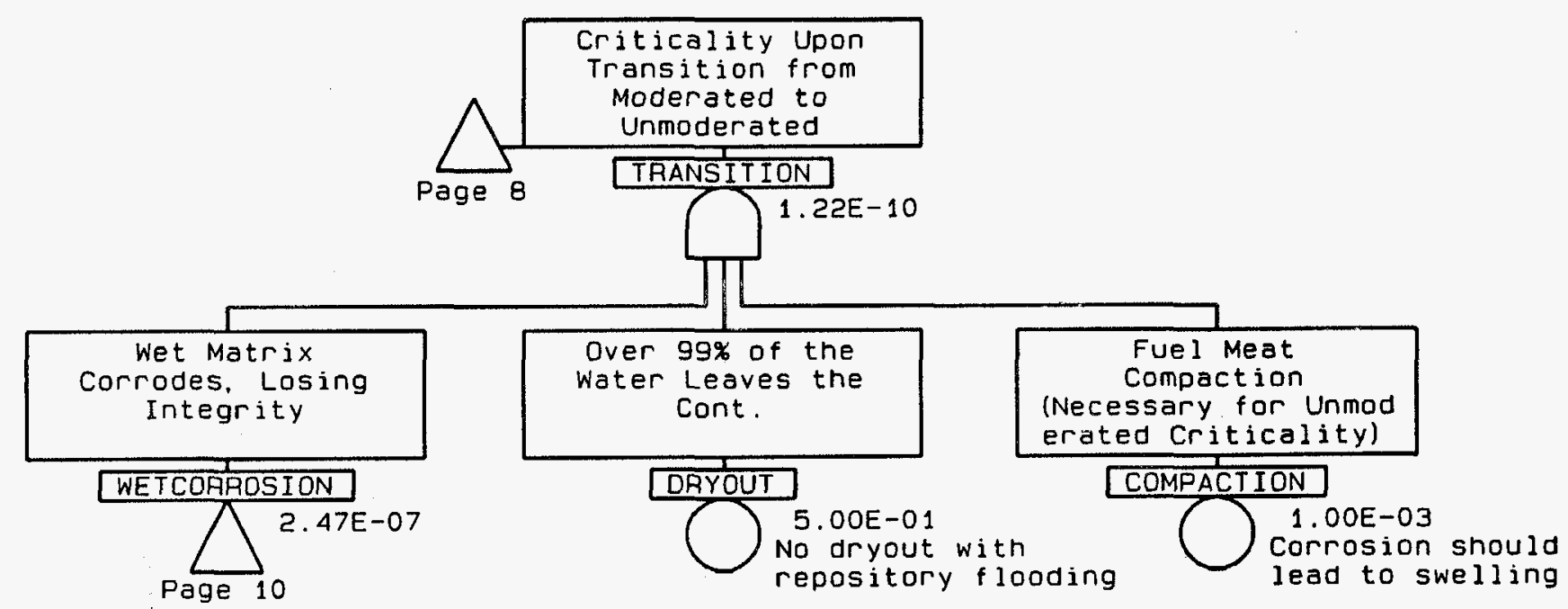

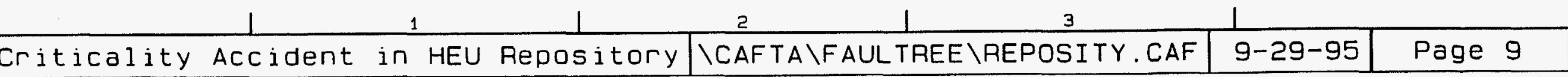




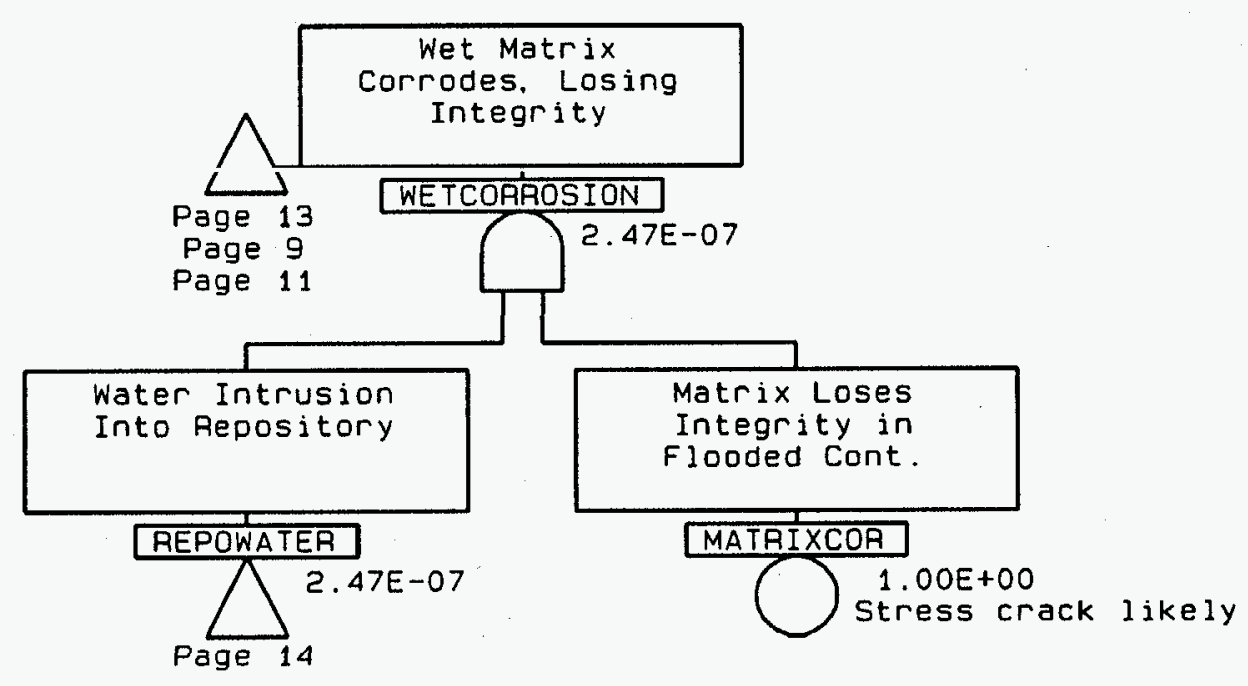

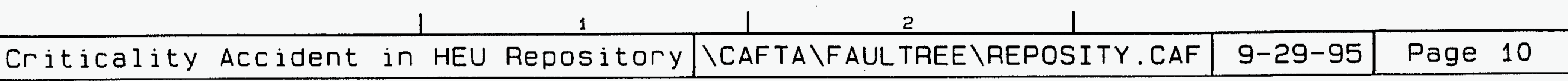




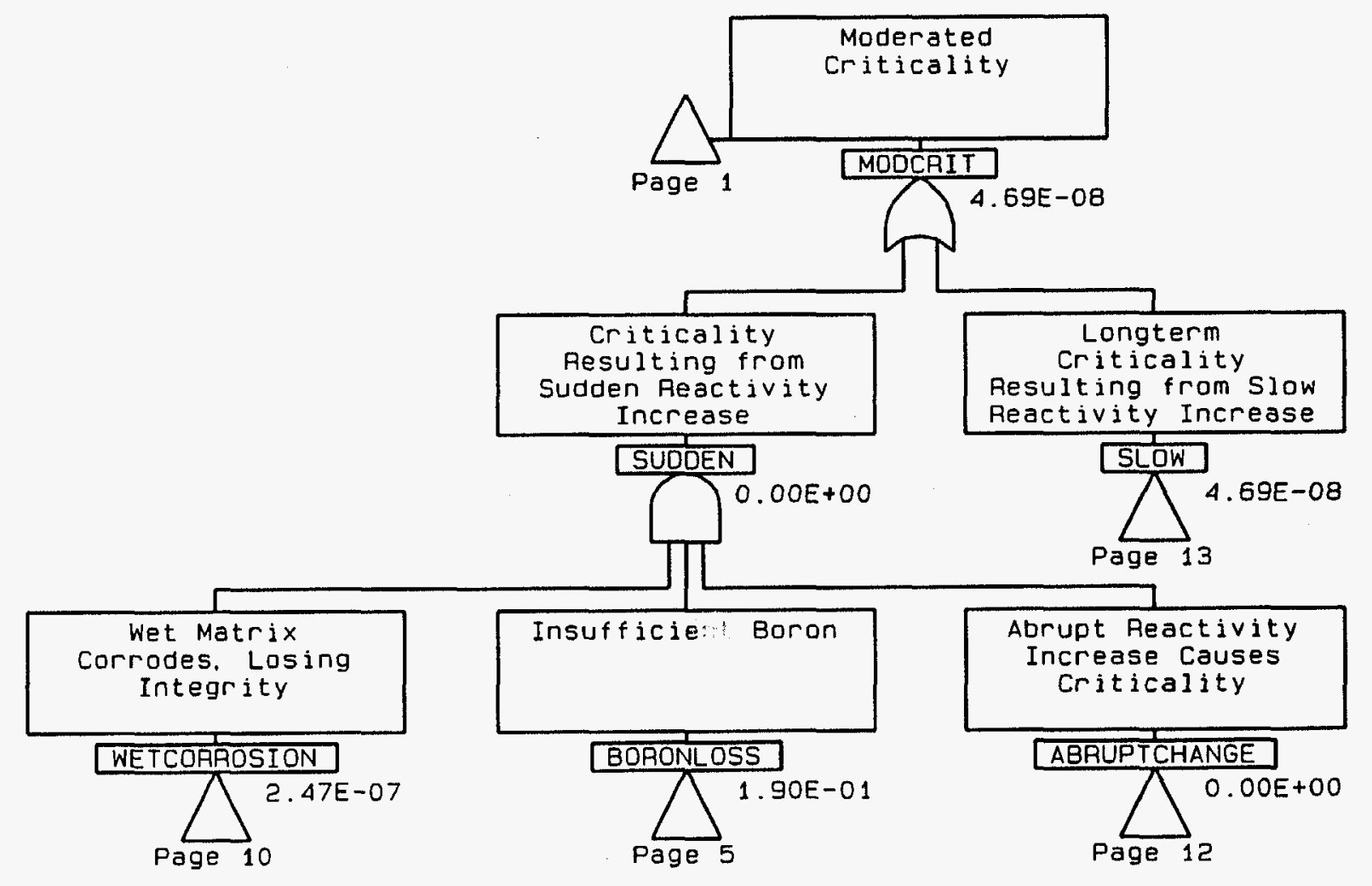

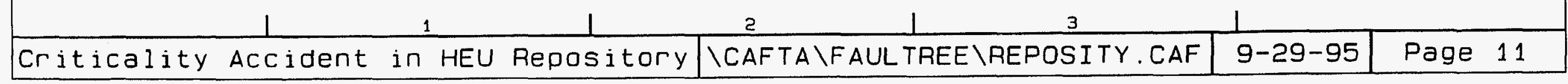




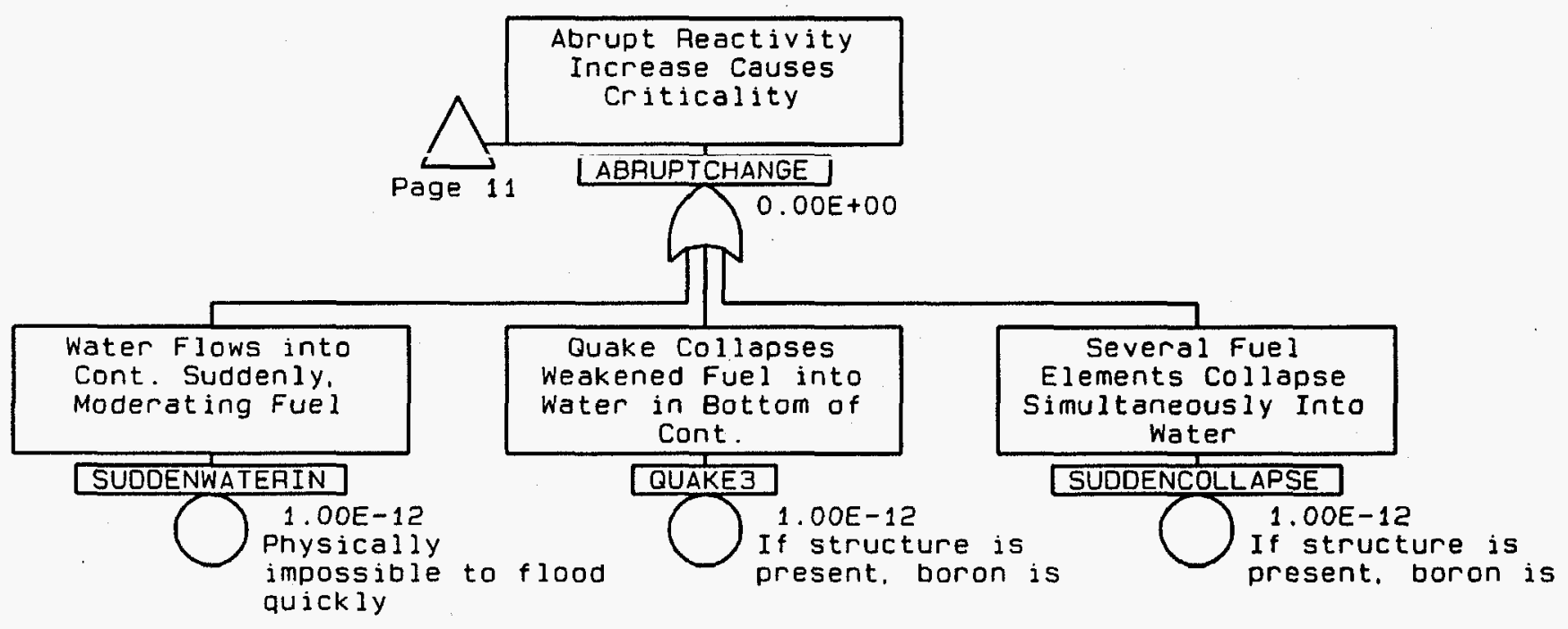

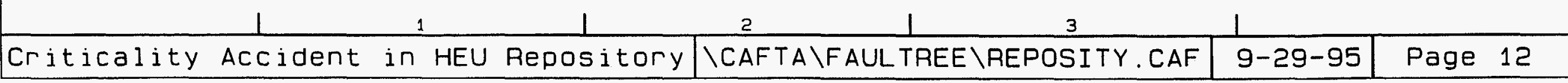




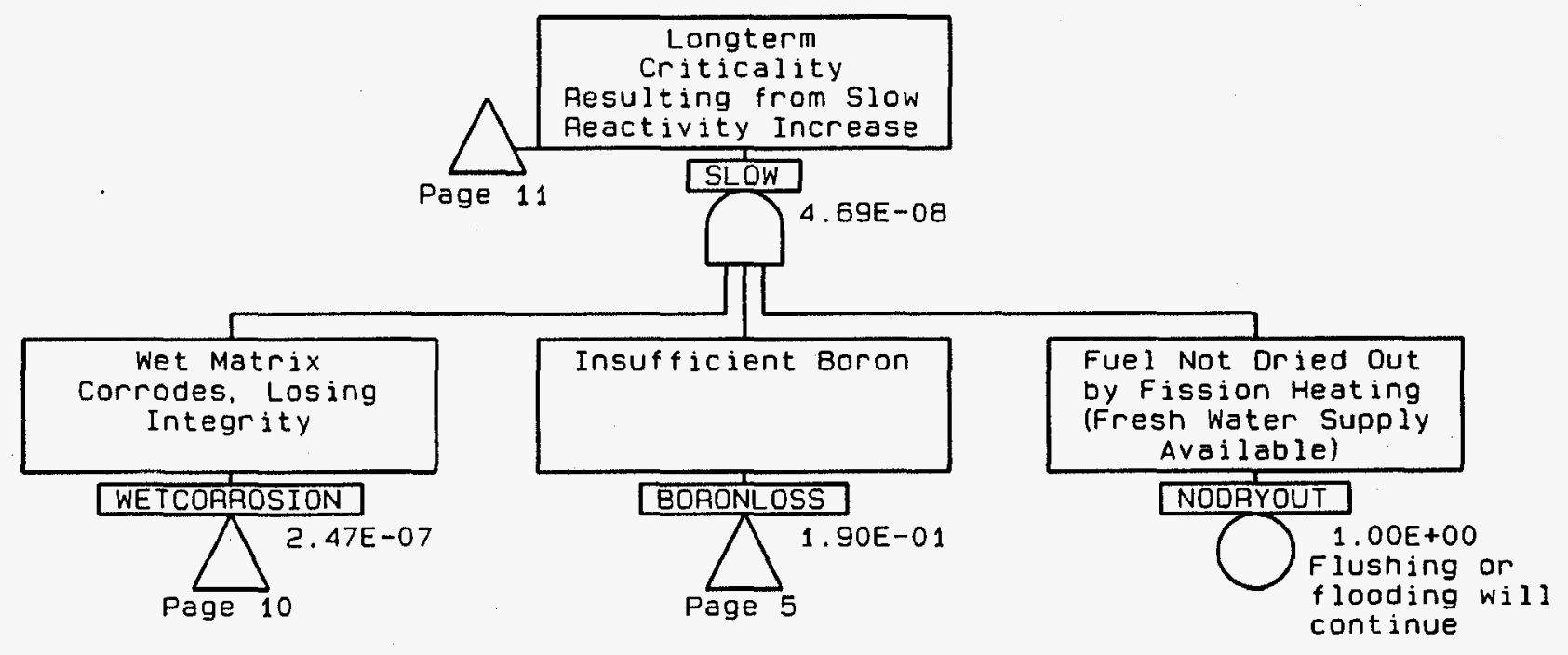

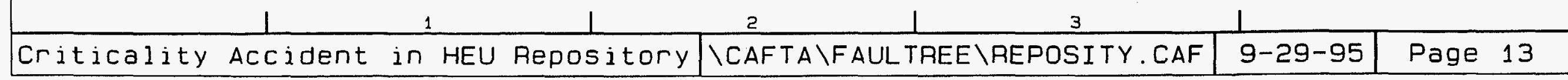




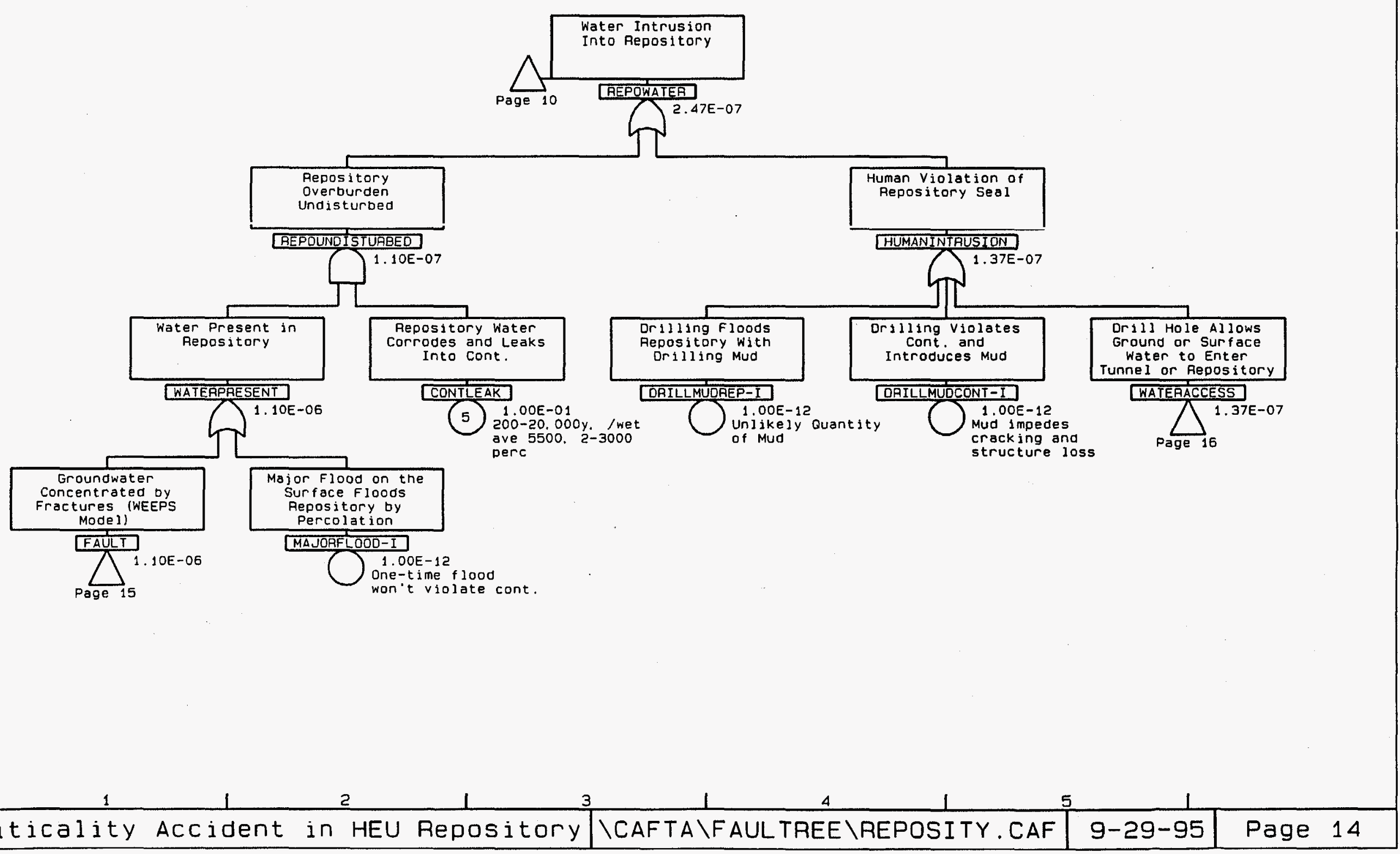




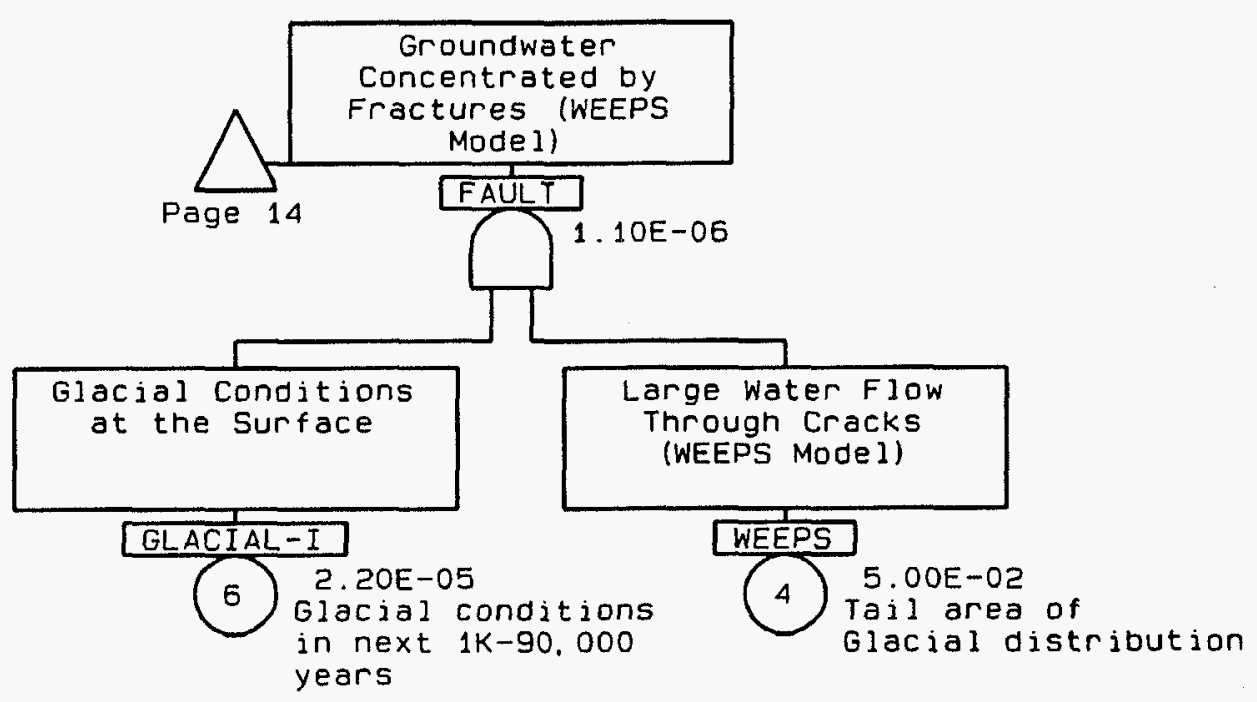

\begin{tabular}{|l|c|c|c|c|c|}
\hline & 1 & 1 & 2 & 1 \\
\hline Criticality ACcident in HEU Repository & \CAFTA \FAULTREE $\backslash$ REPOSITY.CAF & $9-29-95$ & Page 15 \\
\hline
\end{tabular} 


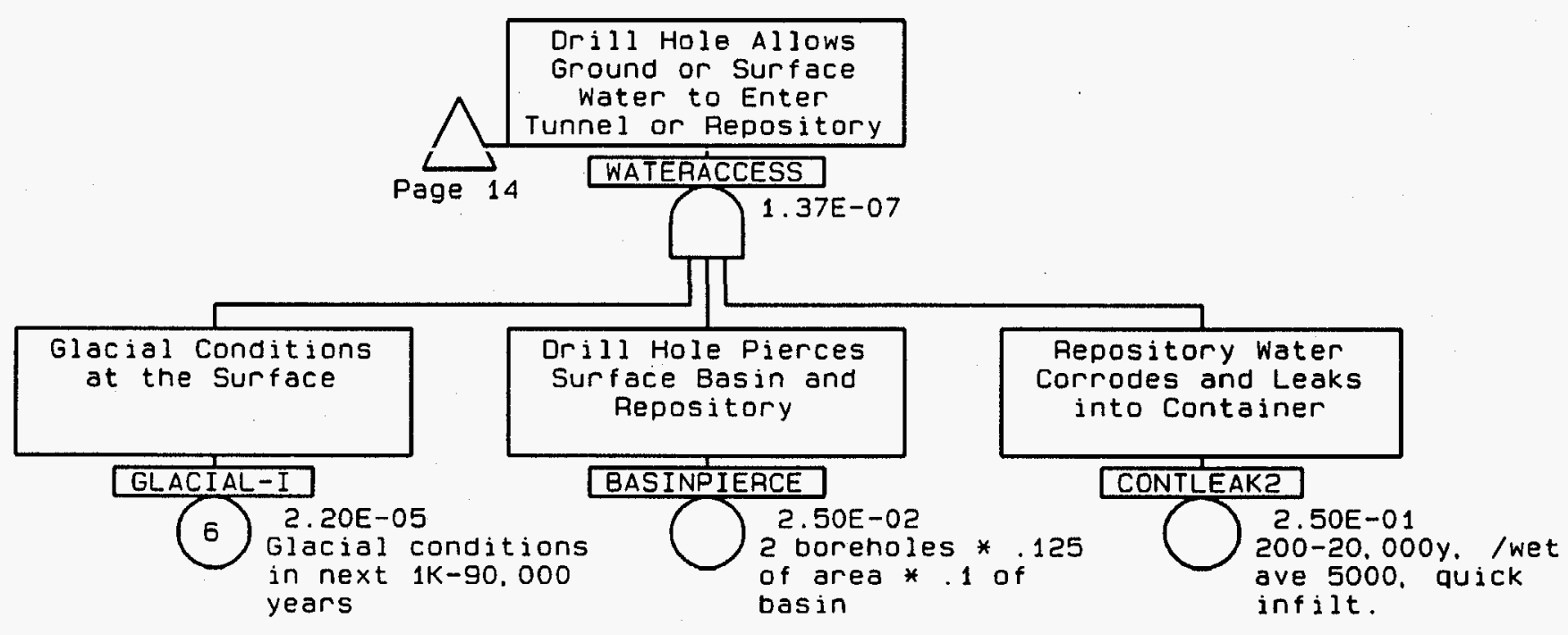

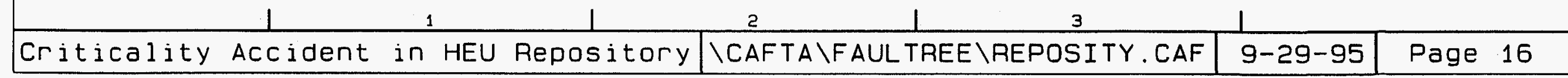




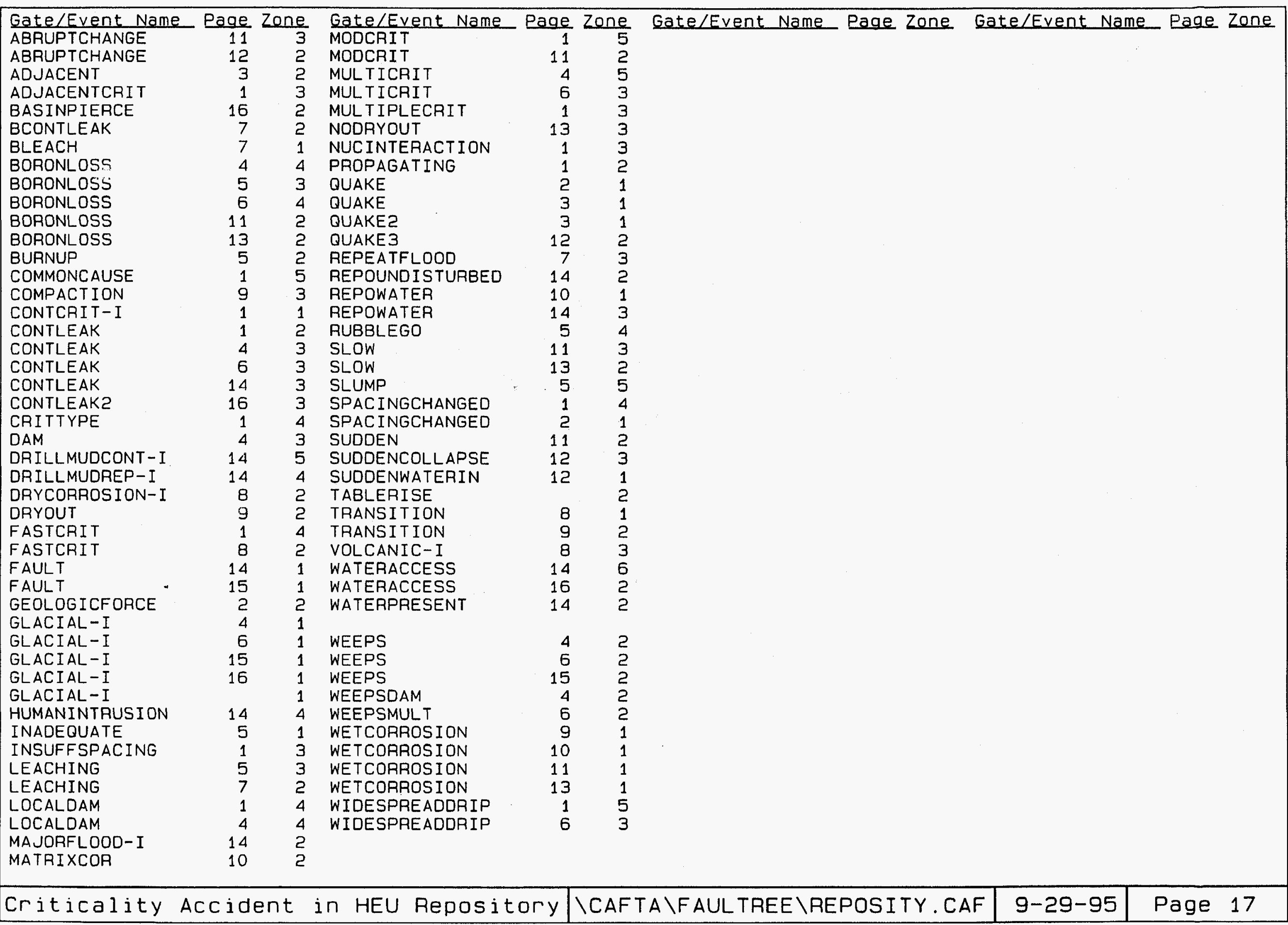

